\title{
The Psychology of Getting Busy: Multitasking as a Consequence of Goal Activation
}

\author{
Ewa Szumowska \\ Jagiellonian University in Krakow \\ Arie W. Kruglanski \\ University of Maryland, College Park
}

Accepted for publication at Journal of Experimental Psychology: General

(C) 2021, American Psychological Association. This paper is not the copy of record and may not exactly replicate the final, authoritative version of the article. Please do not copy or cite without authors' permission. The final article will be available, upon publication, via its DOI: $10.1037 / x g e 0001077$

\section{Correspondence}

Ewa Szumowska, Institute of Psychology, Jagiellonian University, Ingardena Str. 6, 30-060 Krakow, Poland.

ewa.szumowska@uj.edu.pl

\section{Acknowledgements}

The preparation of this paper was supported by a grant no. 1618/MOB/V/2017/0 from the Polish Ministry of Science and Higher Education and from Jagiellonian University grant no. K/DSC/004883 awarded to Ewa Szumowska.

\section{Author Note:}

The Authors declare no conflict of interest. The results were presented at the EASP small group meeting "Cognitive Conflicts: Taking a Cognitive Perspective on Social Phenomena" in Tübingen on 3-6 July, 2019. Data and analysis scripts can be found at osf.io. 


\begin{abstract}
With the constantly increasing popularity of human multitasking, it is crucial to know why do people engage in simultaneous task performance or switch between unfinished tasks. In the present paper, we propose that multitasking behavior occurs when people have multiple active goals, the greater their number, the greater the degree of multitasking. The number of currently considered goals is reduced where one goal's significance overrides the others, reducing the degree of multitasking. We tested these hypotheses in a series of six studies in which we manipulated either goal activation or goal importance and investigated how this affected the degree of multitasking. The results showed that the more active goals participants actively entertained, the more likely they were to plan to engage in multitasking (Study 1 \& 5), and the more often they switched between tasks (Study 2). They also multitasked more under high interruption condition assumed to activate more goals than low interruption condition (Study 3). Further, we demonstrated that the degree of multitasking was significantly decreased by reducing the number of simultaneously considered goals, either via increasing the relative importance of one of the goals (Study 4) or via inducing greater commitment to one of the goals through a mental contrasting procedure (Study 5). Study 6, carried out in an academic context, additionally showed that the importance of a class-related goal negatively predicted media multitasking in class. The results thus show that goal activation is the underlying mechanism that explains why people multitask.
\end{abstract}

Keywords: multitasking, multiple goals, task switching, goal activation, goal importance. 


\section{Introduction}

Multitasking is not new. People have been likely combining and interleaving tasks from times immemorial (Courage et al., 2015) and the first studies on multitasking date back to the end of the $19^{\text {th }}$ (Solomons \& Stein, 1896; Welch, 1898) and the beginning of the $20^{\text {th }}$ century (McQueen, 1917; Jersild, 1927). Yet recently the prevalence of multitasking has reached an unprecedented scale. Researchers argue that it has become "the new normal" (Courage et al., 2015 , p. 6) and that nowadays people constantly multitask at home, at school and at work (Buhner et al., 2006; Carrier, Rosen, Cheever, \& Lim, 2015; Salvucci \& Taatgen, 2011). This uptick in the popularity of multitasking has spurred considerable scientific interest in the topic resulting in a surge of studies on multitasking in recent decades. For the most part, these studies focused on performance (e.g., Janssen et al., 2015; Pashler, 1994; Salvucci \& Taatgen, 2011) and on identifying the characteristics of an efficient multitasker (e.g., Buhner et al., 2006; Colom et al., 2010; Sanbonmatsu et al., 2013; Szumowska \& Kossowska, 2016). Recently, the question of the consequences of multitasking has also been receiving attention (e.g., Carrier et al., 2015; Courage et al., 2015; Rothbart \& Posner, 2015). However, the question of why people engage in multitasking and when they are most likely to do so has received relatively less scientific attention, even though it seems crucial to a full understanding of the phenomenon.

Building on the goal systems theory (Kruglanski et al., 2002, 2015), we presently argue that people multitask when they have several active goals of equal (or nearly so) importance. Particularly, we assume that although people typically operate in multiple goal environments, the number of goals they keep active and the behavior-driving power of those goals varies across persons and across situations. The more an individual entertains multiple goals, the more they multitask. One factor that limits the number of goals that are considered concurrently is the relative importance of those goals: when one goal is of particular 
importance, other goals tend to be suppressed, hence less multitasking is to be expected. Consistent with this analysis, in what follows, we present a series of studies in which we manipulate either goal activation or goal importance and show that, keeping all else equal, multitasking increases with the number of active goals but decreases when one goal considerably gains in importance over the others.

We thus postulate that goal activation and goal importance (a factor that limits the number of active goals) are the underlying mechanisms of people's engagement in multitasking. These mechanisms explain why multitasking increases in some environments (e.g., busy offices), under certain circumstances (e.g., workload), or when certain means (e.g., multifunctional electronic devices) are used, and why it decreases when one task is prioritized over others (e.g., when a deadline on one of the tasks draws near). Such conceptualization also helps to analyze multitasking across different domains (e.g., everyday tasks, academic goals), different types of multitasking (e.g., task-switching paradigm, media multitasking, dealing with interruptions), and different levels of analysis (from simple experimental tasks to higher-order goals). It also provides a theoretical framework that integrates findings from the goal literature with studies on multitasking across multiple domains, such as cognitive psychology, human-computer interaction, organizational psychology, media research and other studies in applied settings.

\section{Defining multitasking}

Goals are subjectively desirable states of affairs that the individual intends to attain through actions (Kruglanski, 1996; Kruglanski \& Kopetz, 2009). According to the goal systems theory, goals and means of their attainment are cognitively represented (Kruglanski et al., 2002, 2015). Moreover, goals are related to means and vice versa in different ways, thus creating different goal-means configurations. In other words, people have an idea of what they want (the goal) and how to attain it (the means). This is how a task can be seen. Mainly 
defined as a set of activities engaged in for the purposes of attaining a goal (e.g., Bedny, Seglin, \& Meister, 2000; Cascio, 1978; Poposki \& Oswald, 2010; Sanbonmatsu et al., 2013), a task represents a means to a given desired end state ${ }^{1}$. We thus define a task as an activity, or a set of activities, which constitute a means to a goal. Multitasking would thus take place when in a given time block people switch between or simultaneously perform these activities.

Rather than a dichotomy, we see multitasking as a continuum wherein the degree of multitasking is represented by the frequency of switching between tasks. On one end, there are very frequent switches, with simultaneity being a special case; on the other end, the switches are much less frequent (e.g., every half an hour or more) (see also Salvucci \& Taatgen, 2011).

The foregoing portrayal is closely related to the classical research on selective attention where Posner (1990) distinguished two types of attentional activities involved in multitasking: divided attention and rapid attention switching. In the former, individuals process more than one stimulus at the same time, whereas in the latter they only process one stimulus at a time but rapidly shift back and forth between the stimuli. Both, however, typically lead to slower and more error-prone performance (Posner, 1990).

The present definition of multitasking is also in line with previous conceptions in which multitasking was treated as either simultaneous task performance (e.g., Buhner et al., 2006; Ishizaka, Marshall, \& Conte, 2001; Poposki \& Oswald, 2010; Rubinstein, Meyer, \& Evans, 2001; Todorov et al., 2015) and/or as switching between tasks in a given time block (e.g., Burgess, 2000; Chen \& Yan, 2016; Hambrick, Oswald, Darowski, Rench, \& Brou, 2010; Law, Logie, \& Pearson, 2006; Monsell, 2003; Rogers \& Monsell, 1995; Szumowska,

\footnotetext{
${ }^{1}$ We assume that the designation of means and goals is relative within a motivational hierarchy at which top resides a basic need (e.g., competence). In other words, whereas a task (say studying) is a means to a goal of getting a good grade, the latter, in turn, is a means of getting to a good college which is a means to affirming one's competence. Similarly, performance of a task can be seen as a goal, and getting to the school in time, a means to being able to perform the task, etc.
} 
Popławska-Boruc, \& Kossowska, 2018). The latter has been especially emphasized given the findings that due to sensory and cognitive bottlenecks the human brain is incapable of simultaneous processing, and concurrency - if it occurs - is only apparent. What in fact happens is very rapid switches of attention (e.g., Pashler, 1994; 1999; Salvucci \& Taatgen, 2011; Srivastava, 2013; concurrency is, however, possible in certain circumstances, e.g., walking and chewing gum).

Admittedly, very rare switches between task goals are not typically regarded as multitasking which is defined as switches within a specific time block. The latter, however, can mean different lengths in different contexts; accordingly, some authors suggest that a time block should be at least as long as the average length needed to complete one iteration of the behavior of interest (Weick, 1968), others maintain that participants' experience of engagement and closure is the best indication of what a time block is (Waller, 2007), and yet others maintain that a time block typically lasts one hour or less (Konig, Oberacher, \& Kleinmann, 2010; Konig \& Waller, 2010).

In the present paper we address the degree of multitasking (see also Janssen et al., 2015; Konig et al., 2010; Salvucci \& Taatgen, 2011). Rather than attempting to determine whether our participants multitask or not, we focus on their level of multitasking, with higher levels of multitasking being defined by longer periods of simultaneous task performance and more frequent switches (absence of switching between unfinished tasks being taken to mean a perfectly sequential, i.e. non-multitasking, performance) $)^{2}$.

\footnotetext{
${ }^{2}$ Our definition is thus devoid of assumptions as to what exactly motivates multitasking or whether it is a strategic decision to maximize gain or a self-regulatory failure. Some researchers define multitasking as the behavior motivated by the preference to multitask (Bluedorn et al., 1992; 1999) or the need for the speedy task performance and the desire to get more things done (e.g., Bluedorn \& Jaussi, 2007). Others argue that it stems from (self-)interruptions, impulsivity or the inability to inhibit distraction (e.g., Adler \& Benbunan-Fich, 2013; Sanbonmatsu et al., 2013; Konig et al., 2010). Whereas the former would suggest that multitasking is a strategic decision to accomplish more goals, the latter would suggest that it is rather a self-regulatory failure. Others would yet add it is an expression of one's preference to multitask over single-task and stems from individual differences (see also Konig et al., 2010; Oswald et al., 2007; Waller, 2007). In the current paper, we focus on the behavior of multitasking (simultaneous task performance or switching between tasks in a given time block) and leave the causes and consequences of this behavior outside the scope of the definition. This allows for a much
} 


\section{Goal activation and goal suppression}

It is a near truism to say that people multitask when they have multiple tasks to be done. The fact is, however, that although people generally have many tasks they want to accomplish, not everyone, or not always, multitasks to the same extent. We argue that multitasking depends on the number of active goals. Since goals are cognitively represented (Bargh, 1990; Kruglanski, 1996; Kruglanski et al., 2002), as with any mental representations they need to be active in order to influence cognition and behavior. In other words, goals stored in memory as desirable end states - have the potential to be activated. Attending to some cues associated with the goal, either internal or external, renders the goal dominant in a given context thus overriding other goals and becoming the driver of behavior in those circumstances (e.g., Altmann \& Trafton, 2002; Carver \& Scheier, 1998; Gollwitzer \& Moskowitz, 1996; Higgins, 1996; Kruglanski \& Kopetz, 2009). Therefore, it is not all the goals that people have but only a subset of goals which are currently active - or a "working set" (Shah \& Kruglanski, 2008, p. 218) - that influence one's choices and behavior in a given situation.

This process is illustrated by the studies of Kopetz, Faber, Fishbach, and Kruglanski (2011). In a series of experiments, these investigators manipulated the activation of background goals and tested how that influences the range of means selected to satisfy the focal goal. The results showed that the presence of active background goals narrowed the range of means to a focal goal and restricted them to only those that satisfied all currently active goals. This so-called multifinality constraint effect shows that a person's choices are guided by all the goals that are active at a given time. A similar idea is also implicit in the notion of satisficing, wherein a person tries to satisfy all concerns present in a given situation,

broader and integrative perspective on multitasking (see De Houwer, 2019, for a similar claim in reference to other psychological constructs). 
often at the cost of sub-optimal performance on each (Simon, 1967; see also Atkinson \& Birch, 1970; Hull, 1938; Lewin, 1951; Neisser, 1963).

Selection of multifinal means, however, is not always possible. When a person has several active goals, each related to a distinct set of activities (i.e., tasks), multifinal solutions are not available. Active goals, however, will still exert their influence on a person's behavior - a person will be motivated to satisfy them all. This might increase multitasking. We thus hypothesize that that the more active goals attached to different sets of activities (tasks) a person has, the greater the degree of multitasking. On the other hand, the fewer the active goals (e.g., due to suppression of some of the goals), the lower the degree of multitasking.

Consistent with the present theorizing, research shows that multitasking occurs under high situational demands (e.g., Kleinsorge \& Scheil, 2015; Konig et al., 2010; Oswald, Hambrick, \& Jones, 2007). However, the direct evidence showing that the degree of simultaneous task performance or the rate of switching increases as a function of the number of active goals is still rather scarce. At the same time, this phenomenon has broad theoretical implications. Given that goals can be activated in many ways, we can show that the same mechanism underlies different instances of multitasking. People might multitask because they have multiple demands ("a lot to do") and deliberately want to keep all of their tasks in mind lest they forget something. At other times they might simply get distracted by some stimuli that appear in their awareness, whether self-generated or triggered by external cues. The latter may remind a person of a delayed intention (this is how event-based prospective memory works, Kliegel, Jager, \& Phillips, 2008; Sanjram \& Khan, 2011), present an opportunity to engage in a new, more enjoyable or rewarding task or identify an entirely new goal. In the present paper, we activate individuals' goals in different ways (by asking participants to recall their own tasks, by reminding them of tasks they were asked to perform in the lab setting or by external interruptions that inject new goals into individuals' awareness). 
As noted earlier, the number of active goals that people address can be limited due to goal suppression, resulting either from one's intentional efforts to stay on task and/or from unconscious attentional inhibition and goal-shielding (Shah, Friedman, \& Kruglanski, 2002) affected by importance of, or commitment to a given focal goal. It therefore follows that an increased importance of one of the active goals can decrease the degree of multitasking. We discuss this issue next.

\section{Goal importance}

The number of active goals a person considers at a given moment depends on the relative importance of those goals (Kruglanski, 1996; Kruglanski et al., 2012; see also Atkinson \& Birch, 1970). The studies by Kopetz et al. (2011) showed that increased importance of one of the active goals reduced the influence of other goals on one's current behavior. Thus, in one study (Study 3) researchers looked at the kinds of foods students were considering for lunch. All participants had relatively equal concern for the goals of food enjoyment and weight control. In one condition, however, the importance of the goal of food enjoyment was enhanced through a mental contrasting procedure (Oetingen, Pak, \& Schnetter, 2001; Oetingen, 2000). The results showed that as compared to a control condition in which the two goals were equally important, participants in the condition in which the importance of food enjoyment was increased listed more foods, including those that were rated higher on taste but also on caloric content (at odds with the weight control goal). These findings were replicated in Study 4, in which commitment to food enjoyment was manipulated via sequential priming; this also showed that when importance of one of the goals was experimentally increased, multifinality constraints were released in a way that participants selected more means towards their focal goal, including also means that undermined the other goal. This was not the case when all goals were seen as equally important. 
Other studies have identified the mechanism that might be responsible for this effect. In a series of experiments, Shah et al. (2002) showed that the activation of a goal to which one is committed inhibits the accessibility of alternative goals, which is reflected in the slowing down of lexical decision times to word labels representing alternative goals (the goal shielding effect). This effect was dependent, however, on goal importance, the more important the focal goal, the stronger the shielding or the inhibition of the alternative goals (see also Kopetz et al., 2011, Study 5).

Similar effects have appeared in studies on prioritization, wherein a task perceived as more important receives more time, effort, and attention than do less important tasks (Cantor \& Langston, 1989; Carver, 2004; Shah, 2005; Simon, 1967; see also Hannah \& Neal, 2014; Louro, Pieters, Zeelenberg, 2007; Schmidt \& DeShon, 2007). Farmer, Janssen, Nguyen, and Brumby (2017) found, for instance, that while performing two concurrent tasks, participants varied how long they spent on one task before switching to the other task depending on the reward (number of points) obtained in each task. Raby and Wickens (1994) examined task scheduling among pilots and showed that higher-priority tasks were more likely to be completed on time, and lower-priority tasks were abandoned as the workload increased (see also North \& Gopher, 1976). Similarly, studies on in-car multitasking demonstrated that when participants were instructed to prioritize safer driving over phone dialing, they interacted with the phone in shorter bursts of activity compared to a situation in which they were instructed to prioritize dialing. In the latter case, they exhibited poorer driving performance (Brumby, Salvucci, \& Howes, 2009; Janssen \& Brumby, 2010; Janssen, Brumby, \& Garnett, 2012).

We therefore assume that increased importance of one of the active goals would diminish multitasking or the rate of switching between tasks as compared to the situation when the same tasks are equally important. In other words, multitasking will be greatest when the active goals are of equal (or almost equal) importance. By contrast, when one goal is 
considerably more important than the other goals, multitasking will decrease. The idea that people focus more on more important goals seems to be well-grounded in the goal literature (e.g. Schmidt \& DeShon, 2007; Zhang, Fishbach, \& Kruglanski, 2007). However, how relative importance of active goals affects the degree of multitasking has not received much scientific attention (cf. Schmidt \& DeShon, 2007; Vancouver, Weinhardt, \& Schmidt, 2010). Here, we investigate the possibility that increasing the importance of various goals, either participants' personal goals or task goals ascribed by the experimenter, diminishes participants' propensity to multitask.

In the present research, we adopt a rather broad perspective on goal importance and define it as anything that can affect the value of a goal (Atkinson \& Birch, 1970; Lewin, Dembo, Festinger, \& Sears, 1944; Vroom, 1964), the want (desire) to accomplish it (Kruglanski, Chernikova, Rosenzweig, \& Kopetz, 2014) or the magnitude of the need to act upon the goal at a given moment. Importance thus can vary as a function of personal value one attaches to accomplishment of a given task/goal, rewards expected from goal accomplishment (either tangible external rewards, e.g., money, or intangible ones, as satisfaction, the sense of accomplishment, cognitive closure, pleasure/ "fun" derived from the task, etc.). Importance may also vary as a function of the need to act upon the task, which, as proposed by the control theory (Carver \& Scheier, 1998) and current dynamic models of goal pursuit (Schmidt \& DeShon, 2007; Vancouver et al., 2010), changes with the discrepancy between the current and desired state and with the approaching deadline for meeting the desired state. In the current studies, we experimentally manipulate goal importance, either in a direct manner (via instructions and points) or indirectly (via mental contrasting procedure, Oetingen, Pak, \& Schnetter, 2001) as well as measure subjective importance participants ascribe to their personal goals. 


\section{Overview of the present research}

To test our hypotheses, we ran 6 studies in which we manipulated goal activation or goal importance and investigated how it affected the degree to which participants engaged in multitasking (or planned to do so) (two additional studies are reported in the Supplementary Materials). In all our studies, we focused on engagement in multitasking rather than on multitasking ability or performance ${ }^{3}$. We quantified the degree of multitasking either by measuring temporal overlap between tasks (the greater the overlap, the greater the degree of multitasking), or by frequency of switching (the more switches, the greater the degree of multitasking) (for a similar approach see Segijn et al., 2017; Szumowska et al., 2018; Yeykelis et al., 2014).

In Study 1 (and 1B presented in the Supplementary Materials), we activated participants' goals by asking them to identify their tasks; we then asked them to graphically plan them in a calendar. We checked whether the number of active goals (represented by the number of identified tasks) was related to the indices of multitasking calculated on basis of participants' graphical plans. We expected that the more active the goals, the greater the degree of multitasking. In Study 2, we asked participants to perform multiple tasks between which they could switch freely. Additionally, we manipulated goal activation and checked whether this affected the number of switches between tasks. We expected more switches in the goal activation (vs. control) condition. In Study 3, we manipulated goal activation by presenting participants with more or less frequent interruptions (high and low interruption conditions, respectively). We expected greater multitasking in the high (vs. low) interruption condition. In Study 4, we again asked participants to perform multiple tasks but additionally manipulated goal importance (via instructions) and checked whether that affected the number of switches between tasks. We expected fewer switches in the increased goal importance

\footnotetext{
${ }^{3}$ Results for performance and accompanying discussion are presented in Supplementary Materials.
} 
condition compared to the condition in which all goals were equally important. In Study 5, we used the same planning procedure as in Studies 1 and 1B, but this time we increased the importance of one of participants' goals (via the mental contrasting procedure) and investigated whether this affected multitasking indices obtained from the planning task. We expected lower degrees of multitasking in the increased importance (vs. control) condition. Finally, in Study 6 we measured the importance of one goal (related to class performance) and checked whether it was related to multitasking as represented by engagement in another goal

(related to mobile phone use). We expected that the greater the importance of the class-related goal, the lower the degree of multitasking by doing things with the phone.

Data and analysis scripts from all studies can be found at osf.io.

\section{Method}

\section{Study 1}

The aim of the study was to test whether there is a relationship between the number of active goals and the degree of multitasking. Here, we activated participants' goals by asking them to identify their typical everyday tasks. We assumed that tasks on participants" "to-do" list constitute the goals they plan to attain that day. We then asked participants to graphically arrange these tasks in a comprehensive plan in order to determine the degree of multitasking. To that latter end, we calculated multitasking indices in each plan and tested for the hypothesized relationships. We hypothesized that the more active goals (i.e., identified tasks), the greater the degree of multitasking.

\section{Participants}

A sample of $N=177$ (96 women, 81 men) users of the Pollster research platform took part in an online study. The sample size was determined based on a priori power analysis (G*Power 3.1, Faul, Erdfelder, Buchner, \& Lang, 2009), which showed that a sample of at least 153 participants would be needed to obtain a power of .80 to detect a correlation of $\rho=$ 
.20. Participants had a minimum of higher education and were aged between 19 and $59(M=$ $18.9, S D=6.41)$. They were compensated for participation in the study based on the rates accepted by the platform. Only those who correctly completed the study were included in the final analyses. These were participants who reported understanding the task instructions and completed the plan in line with the instructions (see the description of the procedure). The final sample comprised $N=153$ participants ( 84 women, 69 men) with a mean of age of $M=$ $28.5(S D=6.32)$. All participants provided online informed consent for participation in the study. The research was approved by the local Research Ethics Committee.

\section{Measures}

Goal activation. To activate participants' goals, we merely asked them to identify up to 10 tasks they performed during their typical day. We asked them to identify tasks that were neither too general (e.g., "work" or "studies"), nor too specific (activities that take several minutes to complete). Instead, we instructed participants to identify activities they considered as separate goals when they usually created plans "in their head". We also encouraged them to identify tasks from different life domains (school, work, social life, entertainment, etc.). Example tasks identified by participants were "cleaning the apartment", "studying for an exam", "reading a book", "working on a report" and "meeting friends".

Plan-Your-Day task. We then asked participants to graphically plan their day. We presented them with a screen that looked like a page from an electronic calendar (see Figure 1) and asked them to arrange their tasks within the plan. The instructions read:

Now you will be asked to plan the rest of your day. The next screen will display a calendar page. Next to it, the tasks you identified in the previous step will be presented. When you click on a task, a new window, in which you can select start and end hours, will be presented. A pop-up window will appear in which you should select your level of attention: if you plan to work on one task at a time, select the 0 $100 \%$ option (this is the default option and means that your attention will be devoted to one task at this time); however, if you know that you will be working on several tasks at the same time, divide your 
attention accordingly. If you work on two tasks at the same time, first set the attention level for the first task (e.g. $0-50 \%$ ) and then for the second task (e.g., 50-100\%). Attention does not have to be divided in half and you can split it as you choose (e.g., 0-80\% for the first and $80-100 \%$ for the second task, or between three or more tasks).

Tasks can "interlock" and "overlap". If you do not perform a task in one go, place it in the calendar several times (each time you click on a task, you can add it again). This means that if you perform a task in steps, with a break or with another task in between, you need to represent it as several separate blocks.

It is very important to us that the plan you create reflects the way you will work on tasks. If you plan to work on given task in steps or perform some tasks in parallel, make sure it is represented in your plan. Blocks can take from 15 min to several hours. Please remember that blocks represent the time blocks your plan is built with. Remember: 1) Tasks can be freely divided and split (one task can be represented by a number of different size blocks); 2) If you do not perform a task in one go, make sure it is represented as several blocks; 3) Several tasks can be performed at the same time (remember to share attention accordingly); 4) Tasks can interlock and overlap; 5) Blocks can be small or large - it is up to you.

At any time during the task, participants could go back to the instructions and read them again. There was no time limit. 

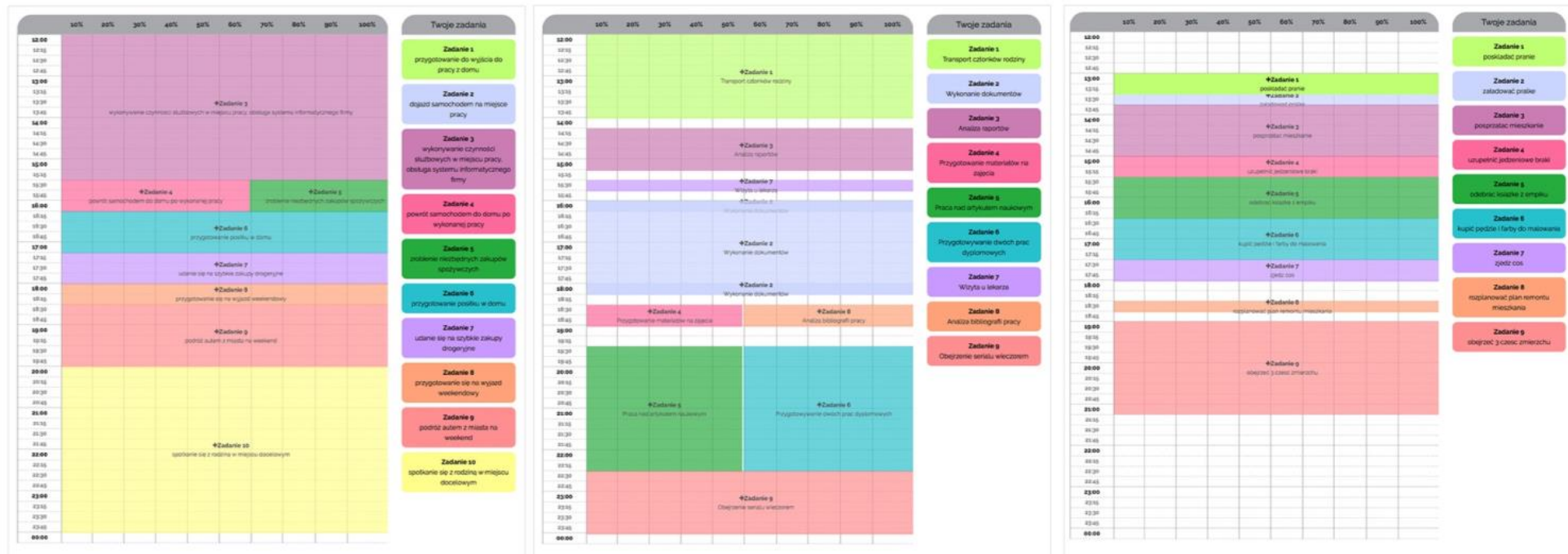

Figure 1. Example plans participants created in Study 1. The first plan is pretty "packed" and presents a mostly sequential strategy with only two overlapping blocks. In the second plan, more overlaps are shown (temporal overlaps can be represented as parallel blocks with attention split between them, or as a spatial overlap wherein one task starts before the previous one ends, and they thus share some common area in the plan). The third plan is entirely sequential (i.e., no multitasking is involved). There are no overlaps and each task is represented by one block (each task is started and finished in one go).

In order to estimate the degree of multitasking, the following indices were calculated: 1) the number of blocks, i.e. the total number of blocks as well as the mean number of blocks per task (number of blocks divided by the number of tasks); 2) mean block duration; 3) overlapping blocks, i.e. the number as well as the percentage (the number of overlapping blocks relative to all blocks); 4) duration of overlap, or the total time that two or more tasks were planned at the same time, i.e. the sum of all overlaps as well as the percentage (total time of overlap relative to the whole time planned for all tasks). We assumed that the more 
blocks and shorter their average duration (controlling for the total number of tasks), the greater the degree of multitasking; numerous or short blocks represent breaking of tasks into smaller chunks, which is characteristic of an interleaving (switching) strategy. We also assumed that the more overlapping blocks and the greater the overall duration of overlap (relative to the total number of tasks), the greater the degree of multitasking (temporal overlap is also a defining feature of multitasking, Adler \& Benbunan-Fich, 2012; Rubinstein et al., 2001).

\section{Procedure}

The study was run online. After providing informed consent and basic demographic information, participants were asked to identify up to 10 tasks they perform during their typical day. Subsequently, they were presented with the task planning instructions and proceeded to create their plans. Since participants were asked to plan the rest of their day, the study took place between 12 and 1 p.m. to make sure that all participants had the same amount of time to plan their activities. The procedure was programmed in PHP and took about 20 minutes to complete.

After creating their plans, participants accepted them (in order to save them) and the planning was complete. They were then asked whether they found the task requirements to be clear (on a 1-7 scale from definitely unclear to definitely clear). Participants who found the task to be unclear (marked $<3$ on the scale) were excluded from further analyses. The case was similar for participants who did not perform the task in line with the instructions (six participants identified several tasks in one box, which the system interpreted as one task and made it impossible to later place the tasks in the plan separately, and four participants identified one general task, e.g. "work", which they were explicitly asked not to do).

At the end of the procedure, two questions about planning were presented: 1) I usually plan my tasks in advance, and 2) How I plan my tasks reflects how I work on them. Responses 
were given on a 1-7 scale (from definitely disagree to definitely agree). These questions were meant to check to what extent our participants perceived planning as reflecting their actual performance.

\section{Results}

On average, participants identified $M=7.29(S D=2.73)$ tasks with $M=6.33(S D=$ 2.66) being included in their subsequent plans (excluding the morning tasks, as the planning was to include post 12 p.m. tasks only). Out of the 12 hours available for planning, an average of $M=6.67(S D=3.02)$ hours were planned. This means that in the studied sample, the plans were not "overpacked" and most participants still had some empty (unplanned) spaces in their plans. Participants also differed in how they planned their activities: some planned tasks sequentially, while others adopted a strategy more based on multitasking (for examples, see Figure 1). Table 1 presents descriptive statistics for the task indices.

Table 1

Descriptive statistics for variables measured in

Study $1(\mathrm{~N}=153)$.

\begin{tabular}{lcc}
\hline & $M$ & $S D$ \\
\hline Total number of blocks & 6.83 & 2.96 \\
Mean block duration & 76.52 & 59.46 \\
Mean number of blocks per task & 1.08 & 0.18 \\
Overlapping blocks [no.] & 1.87 & 2.21 \\
Overlapping blocks [\%] & 23.80 & 27.23 \\
Time of overlap [min.] & 43.86 & 75.85 \\
Time of overlap [\%] & 10.77 & 18.35 \\
\hline
\end{tabular}

Since we expected that the more activated goals participants had, the more they would engage in multitasking, we checked the correlations between the number of tasks participants identified and the multitasking indices obtained from the planning tasks. As our data was mostly non-normally distributed, we used robust statistical techniques. Specifically, we 
calculated percentage-bend correlations (Wilcox, 2017) using the WRS2 R package (Mair \& Wilcox, 2017). Percentage bend correlation, $\rho_{\mathrm{pb}}$, is a robust measure of the linear association between two random variables. When the underlying data are bivariate normal, $\rho_{\mathrm{pb}}$ gives essentially the same values as Pearson's $\rho$; however, $\rho_{\mathrm{pb}}$ is more robust to changes in the data and guards against the deleterious impact of outliers among the marginal distributions (Mair \& Wilcox, 2017).

In line with our predictions, the number of identified tasks (presently treated as activated task goals) correlated negatively with the average block duration, $\rho_{\mathrm{pb}}=-.18, p=$ .007 , and positively with the number of overlapping blocks, $\rho_{\mathrm{pb}}=.40, p<.001$, as well as the amount of time in which two or more tasks overlapped, $\rho_{\mathrm{pb}}=.33, p<.001$. Moreover, the correlation with the percentage measure (number of overlapping blocks relative to all blocks) was also significant, $\rho_{\mathrm{pb}}=.29, p<.001$, suggesting that the correlation with the number of overlapping blocks was not a mere effect of having more tasks to fit in the plan. The correlation with the percentage of overlapping times (relative to the total time participants planned their tasks in) was similar, $\rho_{\mathrm{pb}}=.32, p<.001$. The only index which did not correlate with the number of activated goals was the mean number of blocks per task, $\rho_{\mathrm{pb}}=.12, n s$. This, however, might have stemmed from a rather small variation in this variable (see Table $1)^{4}$.

Furthermore, as we defined multitasking as taking place when participants have more than one task/goal (multitasking is not possible with only one task), we rerun the above analyses only for those who included more than one task in their plan (i.e. we excluded 6 participants whose plan included only one task, remaining $N=147)$. The results obtained in

\footnotetext{
${ }^{4}$ Similar results were obtained when we included all participants who took part in the experiment $(N=177)$. The correlations were equal to $\rho_{\mathrm{pb}}=-.11, p=.138$, for average block duration; $\rho_{\mathrm{pb}}=.48, p<.001$, for the number of overlapping blocks; $\rho_{\mathrm{pb}}=.35, p<.001$, for the percentage of overlapping blocks; $\rho_{\mathrm{pb}}=.42, p<.001$, for the overlap time, and $\rho_{\mathrm{pb}}=.38, p<.001$, for the percentage of overlap.
} 
these analyses were similar to the ones presented above. Specifically, the number of identified tasks correlated positively with the number of overlapping blocks, $\rho_{\mathrm{pb}}=.39, p<.001$, with the percentage of overlapping blocks, $\rho_{\mathrm{pb}}=.26, p=.001$, with the amount of time in which two or more tasks overlapped, $\rho_{\mathrm{pb}}=.32, p<.001$, and with the percentage of overlapping times (relative to the total time participants planned their tasks in), $\rho_{\mathrm{pb}}=.31, p<.001$. There was also a negative correlation between the number of identified tasks and the average block duration (although not reaching the conventional significance level), $\rho_{\mathrm{pb}}=-.15, p=.07$,

Additionally, we checked to what extent participants agreed with the statements about planning that we presented to them after the study's completion. The results showed that participants in our sample agreed with the statement that they usually plan their tasks in advance $(M=5.07, S D=1.37)$ and that their plans reflect how they work on their tasks $(M=$ $4.81, S D=1.36$ ). Both degrees of agreement were on the average significantly greater than 3.5 (the midpoint of the scale), $t(152)=14.22, p<.001$, and $t(152)=11.91, p<.001)$, suggesting that the planning measure can be treated as a fairly good approximation of actual performance (see also Fishbach, 2009).

\section{Discussion}

The results of our first study provide initial support for the hypothesis that the more active goals people have, the more likely they are to multitask. We found that the number of activated goals correlated with the number of overlapping blocks as well the amount of time in which two or more tasks overlapped. We also showed that the more goals people had, the shorter the task blocks they used. Importantly, similar results were obtained for percentage measures which take into account the number of tasks participants included in their plans. In other words, the results did not merely stem from the fact that participants had more tasks to fit in their plans. Interestingly, participants with more active tasks tended to use overlapping blocks and parallel tasks even when they had free (i.e., unoccupied) spaces in their plans (on 
average, participants occupied less than $7 \mathrm{~h}$ of their time, and only 3 participants planned $100 \%$ of the time in the calendar). This might stem from the fact that some times of the day are busier than others (for instance, working hours can be busier than late evenings) and some tasks can only be performed at certain times of day (e.g. picking kids from school). Therefore, some time blocks might be occupied by several tasks, whereas others can remain "empty." This, however, only supports are idea that the more goals one feels they need to complete in a given time period (i.e. the busier the time of day), the greater the propensity to multitask.

We should note that in this study participants were asked to identify the tasks they perform on their typical day. However, it is possible that for some participants their typical tasks are not the same as those they planned for the day on which they participated in the study. Therefore, we rerun the study with a slight change in the procedure: instead of asking participants to identify the tasks they perform on their typical day, we asked them to identify the tasks they needed to perform on the day of the study (i.e. today). Also, for exploratory purposes we added an open-ended question in which we explicitly asked participants to describe situations in which they typically multitask (the results of this study are presented in the Supplementary Materials, Study 1B).

The results were in line with the findings of Study 1 and show that the more active goals participants had, the greater their propensity to multitask, as expressed by the shorter time blocks, greater number of overlapping blocks and more time in which two or more tasks overlapped. We obtained significant results also for the percentage measures which indicate the number of overlapping blocks or overlapping times relative to all blocks or the total "busy" time, respectively. This suggests that with an increasing number of goals, participants deliberately planned more of their tasks in a multitasking manner. This is in line with what participants reported when asked when they typically multitask. Their categorized responses are presented in Table 1B in Supplementary Materials and show that the most common 
situation in which participants multitask is that of having too many tasks (and too little time). Thus, participants' spontaneous responses are in line with our hypothesis regarding the effect on multitasking of having several active goals.

\section{Study 2}

The aim of this study was to further test the hypothesis that the more active goals people have, the more likely they are to multitask. This time, however, instead of planning we focused on actual performance and manipulated the number of active goals (recall that Study 1 was correlational and therefore uninformative about causality). We thus asked participants to perform a set of tasks between which they could freely switch. At some point during task performance, we introduced a manipulation in which we reminded participants of either completed or uncompleted tasks. We expected that in the latter condition, due to the experimental manipulation, participants would have more active goals than in the former condition; therefore, they should be more likely to multitask.

\section{Participants}

A priori power analysis ( $G^{*}$ Power 3.1, Faul et al., 2009) for a one-way ANOVA with two groups and a medium effect size $(f=.25)$ showed that a sample size of at least 128 would be necessary to obtain a statistical power at the recommended level of .80 (Cohen, 1988). Therefore, to budget for a possible case of data loss, we recruited 143 participants. There were 116 women and 27 men aged $18-35(M=23.69, S D=3.39)$, with a minimum of high-school education. Participants were recruited by announcements on university websites and local social portals. They received monetary compensation equivalent to 5 USD for participation in the study. The number of switches was not saved for two participants, who were therefore excluded from further analyses. Also, participants who did not follow the instructions (see the Procedure section) were excluded. The final sample comprised $N=134$ participants (108 women, 26 men). 
The study was approved by the local Faculty Ethics Committee, and included informed consent from all subjects.

\section{Measures}

Multiple task procedure. In this study we used a multiple task procedure (Szumowska et al, 2018; Szumowska, Popławska-Boruc, Kuś, Osowiecka, \& Kramarczyk, 2018) in which participants were asked to perform six tasks in a time limit of 40 minutes. Each task was presented in a separate Google Chrome tab. The tasks included: 1) reading an on-line article, 2) watching a video, 3) listening to a radio broadcast, 4) solving a Sudoku puzzle, 5) solving a set of logic problems, and 6) playing an air hockey game. The article, the video and the radio broadcast pertained to the Terracotta Army, and participants were told that after completing the task (or when the allotted time had passed) they would be asked questions about the topic. This was done to make sure that participants indeed performed the experimental tasks. Indeed, after completion of the multiple task procedure, they were asked 5 questions concerning each task (i.e., article, video, and radio broadcast). Participants' performance on all tasks was measured (as they were instructed it would be).

The tabs were presented in a random order and participants were instructed that they could start with any task of their choosing. They were also told that they could spend as much time as they wanted on each task and that they could freely switch between open tabs (they were asked not to close any tabs). The number of switches between tabs was recorded with a special Google Chrome plug-in (see Szumowska et al., 2018) and served as our dependent variable. Performance on each task, although not of our primary interest, was also recorded to make sure that participants indeed performed the tasks as instructed.

Manipulating goal activation. After 15 minutes of working on the tasks, participants were asked to fill out a manipulation sheet. In the control (or goal "deactivation") condition, they were asked to identify the task goals they had already worked on and completed. So, in 
this condition participants wrote about completed task goals or goals that had lost their motivating potential (in Lewinian terms, they had their tension system drained). Other research has shown that perceived progress on tasks can temporarily "turn off" an active goal (Fitzsimons, Friesen, Orehek, \& Kruglanski, 2009; see also Fishbach, 2009) and that accomplished goals are inhibited (post-fulfillment inhibition, Fishbach \& Dhar, 2007; Forster, Liberman, \& Higgins, 2005). All of which suggests that in the control condition participants had fewer active goals.

In the goal "activation" condition, participants were asked to identify the tasks they still needed to complete. So, in this condition participants focused on uncompleted task goals which were still active in their minds (had not lost their motivating potential). Therefore, even though in both conditions participants had the same number of task goals, in the goal activation condition more of those goals were still active compared to the control condition. A similar manipulation was used in other studies (e.g., Kopetz et al., 2011). Only participants who completed the manipulation correctly were included in the final analysis. Hence, participants who did not provide a meaningful answer or identified the tasks that they had completed as well the ones they still needed to complete were excluded (there were 7 such cases).

\section{Procedure}

Participants were tested in groups of up to 7 people. Each worked in a separate cubicle; however, they were asked to start at the same time. While participants were filling out the manipulation form, the experimenter recorded the number of switches. Participants then resumed their work on the tasks and worked until the time (40 minutes from the start of the experiment) was up. After the study's completion, participants answered questions about the content of the article, the video, and the broadcast. They were then debriefed and thanked. At the end of the session, the experimenter recorded the number of switches again and saved 
participants' scores in the Sudoku puzzle and the air hockey game (the scores in the logic puzzles were saved automatically).

\section{Results}

In order to test our hypotheses, we compared the number of switches (our dependent variable) between the two conditions (our independent variable). However, since we expected the differences to be caused by our experimental manipulation, we separately compared the switches before and after the manipulation was introduced. We expected more switches in the goal activation (as compared to the control) condition after (but not before) the manipulation.

The means for the number of switches were $M=21.5(S D=16.1)$ for the control and $M$ $=28.3(S D=18.3)$ for the goal activation condition after the manipulation. Respective means for the number of switches before the manipulations were $M=8.23(S D=6.52)$ in the control and $M=10.4(S D=7.67)$ in the goal activation condition. However, because switches were not normally distributed (see a beanplot of the data in Figure 2), instead of comparing means, we focused on the difference in medians instead (Wilcox, 2015). To that end, we used the pb2gen function from WRS2 R package (Mair \& Wilcox, 2015) which simply uses the differences in medians as a test statistic; appropriate confidence intervals and $p$ values were determined through bootstrap. 


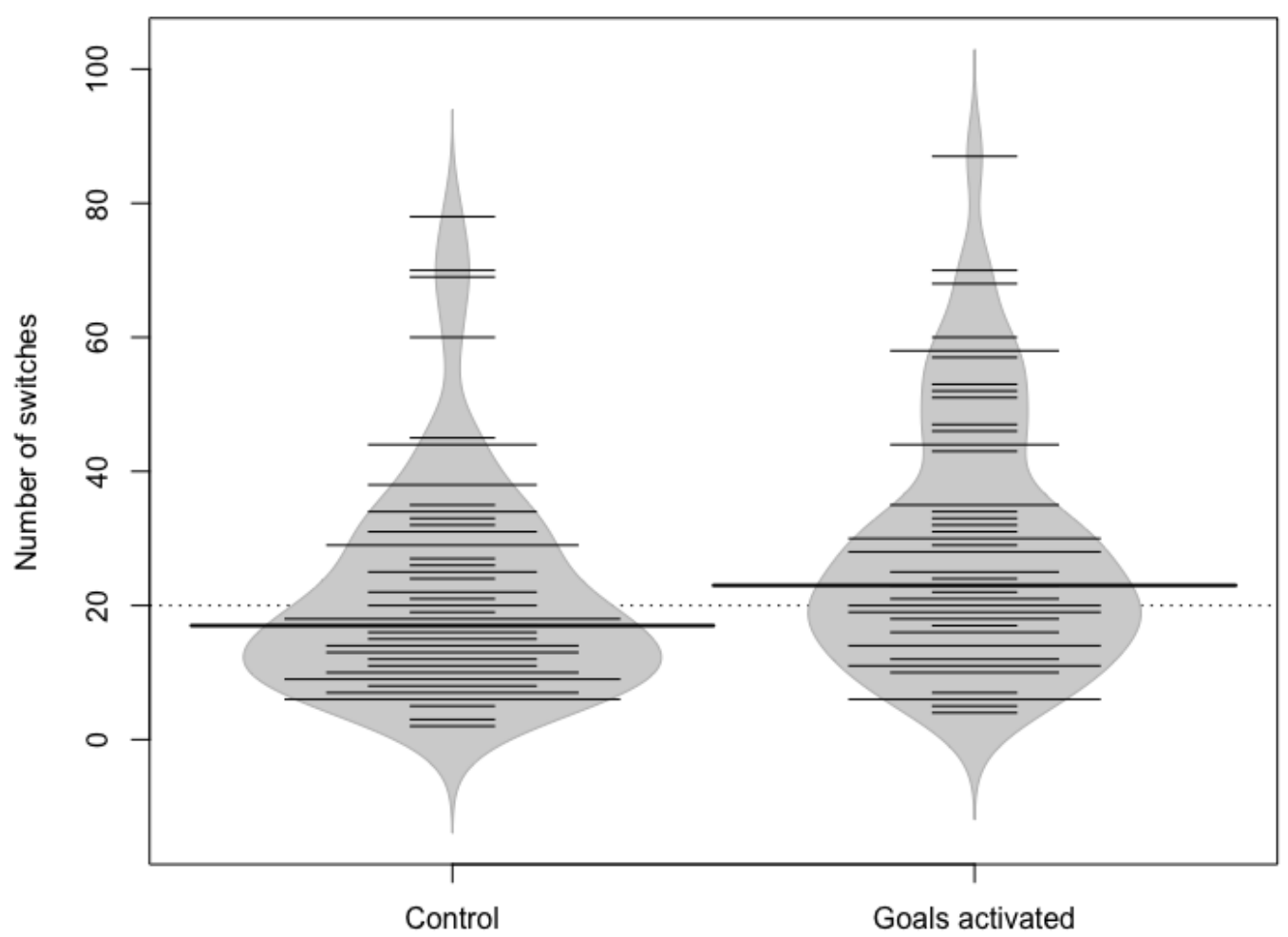

Figure 2. A beanplot for the number of switches between tasks in Study 2 for the control and goal activation conditions separately. Individual observations are represented as thinner horizontal lines (longer lines mean that several participants had the same number of switches). The estimated density of the distributions is marked in grey. Two thicker lines represent medians for the two groups. Beanplots were plotted with the beanplot $\mathrm{R}$ package (Kampstra, 2014; see also Kampstra, 2008).

The results showed that participants switched more often in the goal activation than they did in the control condition: The medians for the goal activation and control conditions were 23 and 17, respectively. A test of differences between medians showed this difference to be statistically significant, diff. $=-6, p=.033,95 \% C I[-13,-1]$. At the same time, the difference in the number of switches before the manipulation was not-significant, diff. $=-2, p=.092$, $95 \% C I[-6,0]$. There also were no differences in performance on any of the tasks between the two conditions (see Table 6 in the Supplementary Materials). 


\section{Discussion}

The results of the study showed that experimentally activated goals significantly increased the rate of switching between tasks. This provides further support for our hypothesis that the more active goals a person has, the greater the degree of multitasking.

We should note, however, that although we expected that our manipulation would influence the number of active goals, this does not mean that participants in the control condition did not have multiple active goals. On the contrary, they still had some tasks to complete and switch between. Indeed, the data shows that participants in both conditions switched pretty frequently, but as those in the control condition had relatively fewer active goals than those in the goal activation condition, their switches were also less frequent. We assume this stems from the fact that salient, active goals motivate people to act upon them and prompt one switch to them in the context of also performing other tasks.

\section{Study 3}

In previous studies, we activated goals by asking participants to recall the tasks they needed to perform on a given day (Studies 1A \& 1B) or by making them realize how many task goals they still needed to complete (Study 2). However, (task) goals can also be activated by interruptions. Indeed, researchers have argued that handling unplanned interruptions is one of the crucial features of everyday multitasking (Bluedorn et al., 1992; 1999; Burgess, 2000; Cotte \& Ratneshwar, 1999; Hall \& Hall, 1990). An interruption can remind one of a delayed intention (Kliegel, Jager, \& Phillips, 2008; Sanjram \& Khan, 2011) or some new goals can arise in the face of interruption. For instance, an incoming phone call or an email alert can invoke the need to answer it or signal a new task. On another occasion, an interruption can divert one's attention away from the main task and offer a more enjoyable activity to engage in (in such a case the new goal would be taking a break or having "fun" with the new activity, as often is the case in media multitasking). In each case, however, one's focus on the main 
task is broken and attention is diverted away and devoted to the new task or shared between the two tasks at the same time (as when one talks on the phone while finishing the email they were writing when the phone rang). Thus, interruptions often activate new goals and thus prompt one to multitask.

We sought to demonstrate these phenomena in Study 3. In particular, we manipulated goal activation by exposing participants to either frequent or less frequent interruptions not related to the main tasks they were performing (high interruption and low interruption conditions, respectively). We then checked how such exposition influenced the degree of multitasking. The latter was indexed as the number of responses to interruptions (i.e. the number of times a person switched away from the main task to perform an action related to the interruption). We expected greater multitasking in the high compared to low interruption condition.

Additionally, we had two types of interruptions: ones that were only visual and ones that additionally emitted sounds (see Procedure section). The idea was that auditory-visual interruptions will be harder to suppress (and thus more efficient in activating new goals) than only visual ones which are easier to block out (see Banbury \& Berry, 1998; Dobbs, Furnham, \& McClelland, 2011; Szumowska \& Kossowska, 2017). Therefore, they should prompt more switches and increase multitasking to a greater extent. ${ }^{5}$

\section{Participants}

Sixty young adults ${ }^{6}$ took part in the study. There were 47 women and 13 men aged between 19 and $29(M=22.78, S D=2.65)$ with a minimum of high school education. They

\footnotetext{
${ }^{5}$ Additionally, we measured participants' need for cognitive closure (Kruglanski \& Webster, 1996; Webster \& Kruglanski, 1994). As irrelevant for the current paper, it was not included in the analyses.

${ }^{6}$ The study was run before a priori power calculation was a common practice. Therefore, we recruited participants in line with the current guidelines (we aimed to have 30 participants per group). However, given that the effect of our manipulation is large, this sample size is enough to obtain power above the recommended .80 level. For instance, to perform Yuen's two-sample trimmed mean test with a large effect size (standardized difference between means $=1$ ) and power at .80 , we would need 23 participants per group (based on formula proposed by Luh et al., 2008). Thus, given the large effect size in our experiment and that the sample size needed for non-normal cases is much smaller for Yuen's than for conventional $t$ test (trimmed sample variance is small
} 
were recruited via announcement on a local social portal and given a monetary compensation for participation in the study equivalent to $\$ 2.5$. The study was approved by the local Faculty Ethics Committee, and included written informed consent from all the subjects.

\section{Measures}

Multiple task paradigm. In this study we used a variant of a multiple task paradigm (Sankaran et al., 2017; Szumowska \& Kossowska, 2017) in which participants are presented with 25 tasks organized in a $5 \times 5$ matrix (see Figure 3 ) and instructed to obtain as many points as possible by performing individual tasks within the time provided (in this case 30 minutes). There were two types of tasks: easy and difficult. Completion of an easy task was worth 3 points but was designed to be less demanding and to take less time. These tasks comprised category generation items (e.g. name five green vegetables), jumbled sentences, and memory recognition items in which participants were presented with a set of objects on the computer screen and were later asked to indicate the location of selected 5 objects. Completion of a difficult task was worth 7 points and was designed to be more demanding and to take more time. These tasks included items from Raven's progressive matrices, number and logic sequence tasks, and word analogies (see Sankaran et al., 2017, for examples). In each task, participants needed to provide responses to (or generate) five items. Points were rewarded in proportion to the number of correct responses. Participants could select the tasks they wanted to perform; however, the tasks were performed in a sequential manner. That is, once started, one could not pause the task and return to it later. Therefore, no multitasking was involved when participants were working on the main tasks.

Additionally, however, there were four interrupters presented in each corner of the screen (see Figure 3). In the left upper corner, there was an alarm clock which could go off at 
any moment during the experiment. When off, it started blinking in red and the sound of the alarm clock was played. To turn it off, one had to click on the alarm clock icon. This interrupter was designed to simulate real-life interruptions such as auditory alerts and reminders generated by computer or smartphone applications. In the right upper corner, there was a mail box. When it started blinking, one could open it and read a "fun fact". The box kept blinking until opened. The item was designed to resemble interruptions such as a blinking icon of a mailbox, instant messenger or a social network application, which often contain entertaining content.

In the left lower corner, there was a cat lying next to the food bowl. At times, the bowl became empty. Then the cat "stood up" and started meowing. It could be "fed" by clicking on the food bowl next to it. It kept meowing until the food bowl was full again. This item was designed to imitate some real-life interruptions that require a quick reaction, otherwise they would pester until responded to. Finally, in the lower right corner, there was a ball floating in the air. Throughout the task the ball floated above the fan but at times the fan turned off (then the "ON" button changed to "OFF") and the ball started dropping. The fan could be turned back on by clicking on the "OFF" button, and the ball went up again. The interrupters were activated in a random order, so that participants could not predict the sequence. 


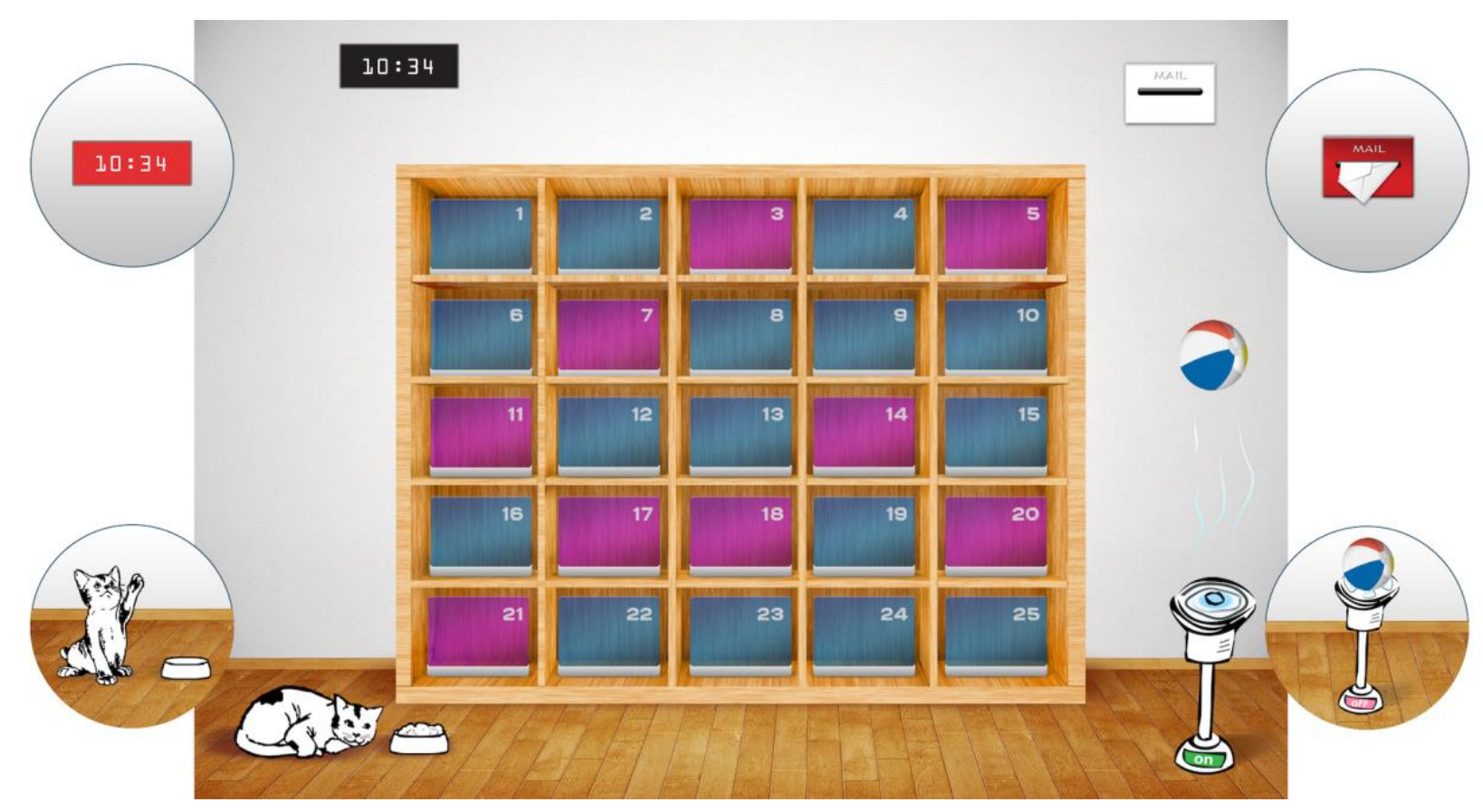

Figure 3. Multiple task paradigm used in Study 3. Main tasks are represented as boxes on shelves. Easy tasks are marked in blue and difficult tasks in purple (there are 16 easy and 9 difficult tasks). In each corner, an interrupter is presented. Most of the time, the interrupters are inactive. However, each of them can get activated at any moment during the procedure. Then, it goes into its "active" state signaled by the change of color, blinking or additional sound. Interrupters in their active state are presented in circles outside the task frame.

Goal activation manipulation. To manipulate the number of active task goals, we varied the frequency of activating interrupters. In the low interruption condition, interrupters were activated every 60 seconds (i.e. every minute one of the inactive interrupters was activated). In the high interruption condition, interrupters were presented every 30 seconds. Thus, there were twice as many interrupters, hence activated goals, in the high compared to low interruption condition. The four types of interrupters were presented equally frequently. 


\section{Procedure}

In the laboratory, after signing the consent form, participants were presented with the multiple task procedure in one of the two conditions (the system randomly assigned participants to either low or high interruption condition). Participants were instructed how to perform the tasks and earn points. They were also informed about interrupters and instructed how to de-activate each of them. They were told, however, that they could, but did not have to, react to the interrupters and it was up to them whether they would engage with them.

Once participants finished reading the instructions and started the first task, they had 30 minutes to complete the procedure. After the allotted time had passed, the study ended and debriefing screens were displayed. Then, subjects were thanked and compensated for their participation. The study was run in groups of up to 7 people, each participant worked in a separate cubicle. The procedure was coded in JavaScript.

Our main variable of interest was the number of responses to interruptions which indicated how many times one stopped their primary task in order to perform an action required by an interruption. In other words, the more responses to interruptions there were, that is, switches away from an unfinished main task - the greater the degree of multitasking. Furthermore, since we had two types of interruptions: auditory-visual (the alarm and the cat) and visual (the mailbox and the fan), apart from analyzing the total number of responses, we analyzed the responses to auditory-visual and visual interruptions separately (similar to Szumowska \& Kossowska, 2017).

Additionally, participants' performance indices were recorded (number of points earned and the number of completed tasks). As performance was not of main interest in this paper, its analyses are presented in the Supplementary Materials. 


\section{Results}

To test our main hypotheses, we checked the differences in the total number of responses to interruptions (our dependent variable) between the two interruption conditions (our independent variable). On average, participants responded to interrupters $M=19.43$ (SD $=4.42)$ times in the low interruption condition and $M=34.91(S D=11.49)$ times in the high interruption condition. Respective medians were equal to 18 and 37 (beanplot is presented in Figure 4).

As in Study 2, we used robust statistical techniques to compare the number of responses to interruptions in the two conditions. Therefore, we tested the differences between medians (pb2gen function, WRS2 R package, Mair \& Wilcox, 2015). The results showed that the difference was statistically significant, diff. $=-19, p<.001,95 \%$ CI [-25, -9.5]. Additionally, we conducted Yuen's (1974) trimmed mean test which allowed us to obtain an effect size estimate. The recommended trimming level of $\gamma=0.2$ was used (if no trimming is involved, Yuen's test reduces to Welch's classical $t$-test with unequal variances, Mair \& Wilcox, 2015). The test yielded similar results as the comparison of medians did, as we obtained a statistically significant difference between conditions, $T_{y}(d f=23.31)=6.55, \mathrm{p}<.001$, with an explanatory measure of effect size equal to $\xi=0.85,95 \% C I[0.74,0.96]$ (confidence interval is based on a percentile bootstrap, see Wilcox \& Tian, 2011, and Mair \& Wilcox, 2015 , for more information). The $\xi$ effect size measure can take values from 0 to 1 , and values 
of $\xi=0.10,0.30$, and 0.50 correspond to small, medium, and large effect sizes. Thus, the effect we obtained in our study was large by these standards.

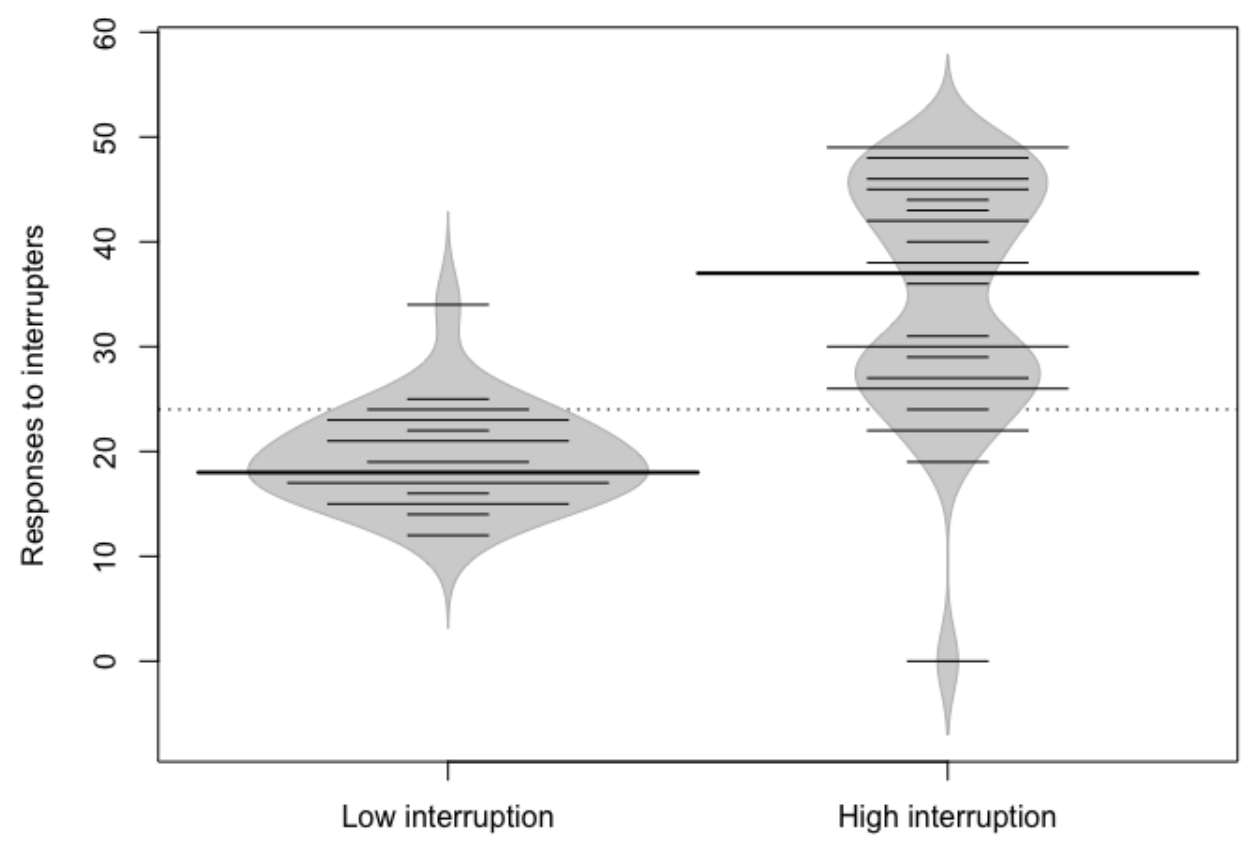

Figure 4. A beanplot for the number of responses to interruptions in Study 3 for the low interruption and high interruption conditions separately. Medians for each condition are marked with thick horizontal lines.

To test our hypotheses regarding the type of an interruption, we ran a between-within subjects ANOVA on the trimmed means using the bwtrim function in the WRS2 package (Mair \& Wilcox, 2015). The results showed a significant main effect of condition, $F_{t}(1$, $20.62)=33.00, p<.001$, a significant effect of the type of interruption, $F_{t}(1,20.64)=45.58$, $p<.001$, and a significant interaction, $F_{t}(1,20.64)=8.38, p=.009$. The results thus indicate that apart from the condition, interruption type mattered as well: auditory-visual interruptions prompted more switches than did visual interruptions. A significant interaction suggests that 
the type of the interruption mattered particularly in the high (compared to low) interruption condition (see Figure 5).

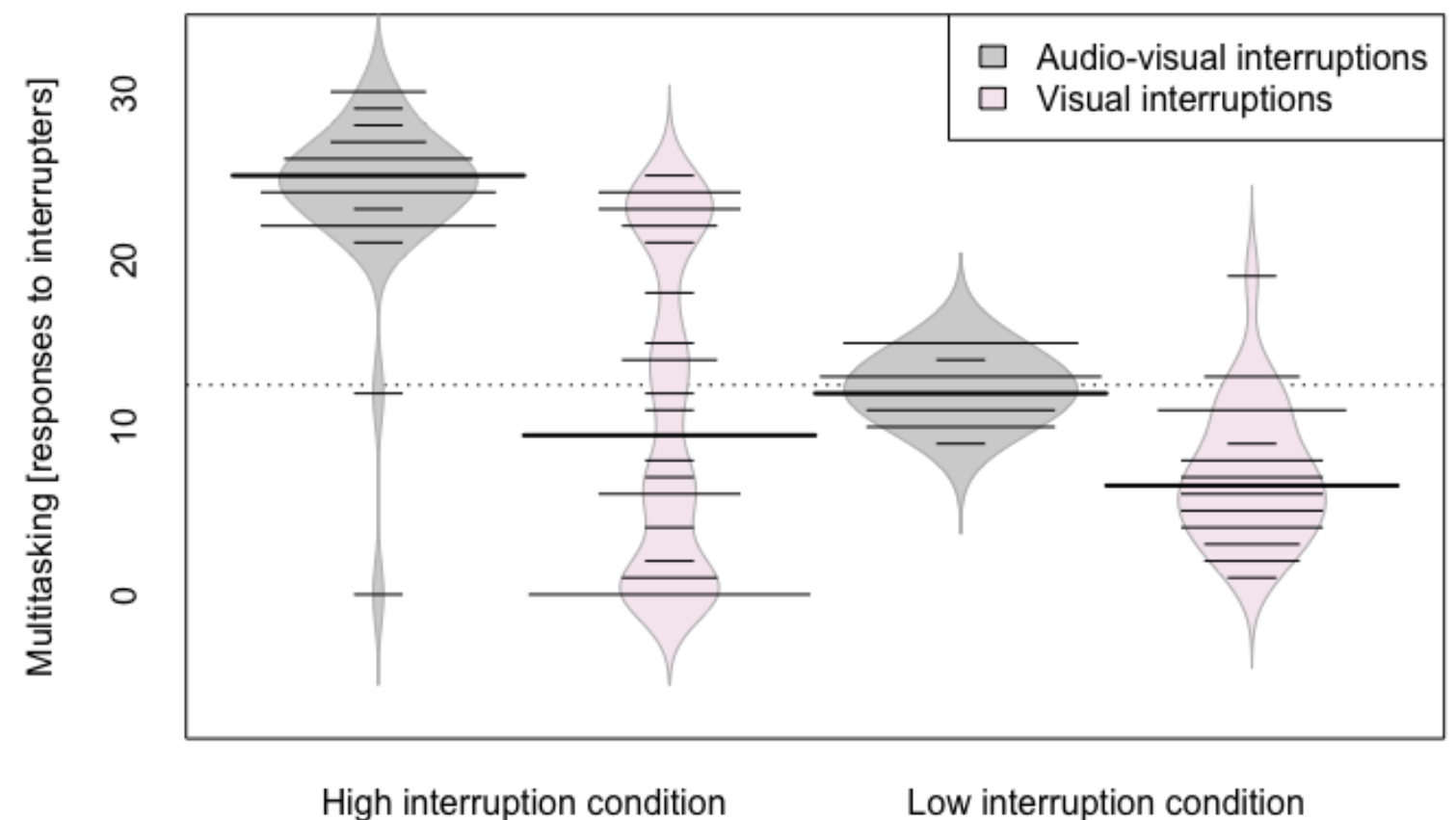

Figure 5. A beanplot for the number of responses to interruptions in Study 3 broken into audio-visual and visual interruptions. Medians for each condition are marked with thick horizontal lines.

\section{Discussion}

The results of this study show that multitasking increases in conditions in which frequent interruptions signal new tasks hence activating new goals (as compared to a situation where interruptions are less frequent). The results are thus in line with the results of the previous studies in this series and show additionally that multitasking increases not only when goals are activated via making people's personal (Study 1A \& 1B) or task (Study 2) goals active, but also via external interruptions. This resembles the distinction between external and internal, or self-interruptions (Adler \& Benbunan-Fich, 2013). Whereas the former refer to environmental cues, alerts, or notifications, the latter point to internal decisions to stop an 
ongoing task and attend to another. Our results show that both types of interruptions have a similar effect in that they both increase multitasking. This is in line with a vast body of research showing that self-interruptions (e.g., Adler \& Benbunan-Fich, 2013; Czerwinski, Horvitz, \& Wilhite, 2004) as well as external interruptions prompt switching and considerably boost multitasking (e.g., Monk, Trafton, \& Boehm-Davis, 2008).

Our results also show that not all interruptions are equal. We expected that auditoryvisual interruptions would be harder to suppress than visual ones, and thus will be more effective in prompting multitasking. Indeed, that was the case. Participants multitasked more often in the high compared to low interruption condition but this was true especially in case of auditory-visual interruptions. This is in line with the literature showing that interruptions' characteristics (such as noisiness, length, difficulty, complexity) matter for the degree of multitasking (e.g., Gillie \& Broadbent, 1989; Monk et al., 2008; Speier, Vessey, \& Valacich, 2003; Szumowska \& Kossowska, 2017). We propose, however, that they may be reduced to the extent to which the interruption is effective in activating a new goal and to its importance (relative to the importance of the main task). The more disruptive the interruption, the more likely it is that one would switch to it. Similarly, the more important (e.g. self-relevant, resource demanding, urgent, etc.) the interruption, the more likely it is that one would switch or devote their attention to it (interruption can cause short or longer pauses on the main task, depending on its type, Salvucci \& Taatgen, 2011). It is also possible that the interruption may activate a goal that is far more important than the main task (as in emergency cases). In that case, it can dominate the main task and one can devote their full attention to the new task. Such increased importance of one of the tasks (relative to the other tasks) will decrease multitasking, an issue we will discuss in the second part of the paper. 


\section{Study 4}

In this study, we wanted to show that goal importance plays a role as well. Similar to Study 2, we asked participants to perform several tasks they could freely switch between. Additionally, however, we manipulated goal importance by instructing one group of participants that all tasks were equally important and the other group that one of the tasks was more important than others. We expected that participants would multitask to a greater extent (i.e., have more switches between tasks) in the equal importance condition compared to a condition in which the importance of one task was increased. The study was pre-registered. ${ }^{7}$

\section{Participants}

A priori power analysis ( $G^{*}$ Power 3.1, Faul et al., 2009) for a one-way ANOVA with two groups and a medium effect size $(f=.25)$ showed that a sample size of at least 172 participants would be necessary to obtain a statistical power at the level of $.90^{8}$. To mitigate potential data loss, we planned to recruit about 185 participants. The collected sample comprised $N=193$ participants (157 women, 31 men, 5 participants did not indicate their gender). Participants were aged between 18 and $38(M=23.52, S D=4.32)$. All had a minimum of high-school education. They were recruited by an announcement on university websites and local social portals. They received monetary compensation equivalent to 5 USD for participation in the study. One participant had a very high rate of wrong answers in the mathematical task (130 wrong answers and 126 right answers, which might suggest guessing) and 4 participants who were in the increased importance condition did not treat the mathematical task as important (indicated less than four on the manipulation check question, see the Measures section). In line with the exclusion criteria stated in the pre-registration form these participants were removed from further analyses. The final sample comprised $N=188$

\footnotetext{
${ }^{7}$ http://aspredicted.org/blind.php? $\mathrm{x}=\mathrm{uw} 8 \mathrm{c} 4 \mathrm{k}$

${ }^{8}$ Since this was our first, "proof-of-concept" study to test the role of goal importance, we wanted to obtain higher power than the minimal .80 .
} 
participants. The study was approved by the local Faculty Ethics Committee, and included informed consent from all the subjects.

\section{Materials}

Multiple task procedure. In this study we presented participants with a triple task scenario that was a modified version of a procedure used in previous studies (Szumowska \& Kossowska, 2017; Szumowska, Kossowska, \& Roets, 2018). In the procedure, three tasks were presented on the computer screen side by side (see Figure 6). In the mathematical task, a person needed to verify whether a mathematical expression presented on the screen was true or false. Responses were given by pressing the " $\mathrm{Z}$ " or " $\mathrm{X}$ " buttons for true and false, respectively. An expression changed once a person had verified it or after 7.5 seconds had elapsed. The number of correct and incorrect verifications (the latter included non-responses) was recorded and presented on the screen. In the monitoring task, a person was asked to watch the position of an arrow. At random points during the task, the arrow started falling and the task was to correct its position (by pressing $\uparrow$ on the keyboard) so that it did not leave the designated area. The number of correct responses and errors (including non-responses) was recorded. In the letter task, participants needed to react to a letter identical to a probe presented below the letter grid. Letters were presented every $750 \mathrm{~ms}$ and probe letters changed every 15 seconds. Responses were given by pressing the space bar when a letter identical to the probe appeared on the screen. Each task thus had its own goal and instructions. Participants were instructed to get as many points as possible by completing all the tasks.

Importantly, switches between tasks were also recorded. Specifically, participants could only react to a given task when they had first clicked upon it. A currently active task was marked with a black frame around it (see Figure 6) and reacting only to this task was possible 
(reaction keys associated with other tasks were non-responsive if a given task had not been clicked upon first). The number of clicks on a task that had not been previously performed represented the number of switches (clicks on already active tasks were non-switch clicks, which were not included in the analyses).

Before the actual testing session commenced, participants went through a training session in which they first familiarized themselves with instructions for the different tasks and briefly performed each of them individually. They then went through a short practice session in which they performed all of the tasks at the same time. Finally, they were presented with a testing block which lasted about 5 minutes. The entire procedure was coded in JavaScript.

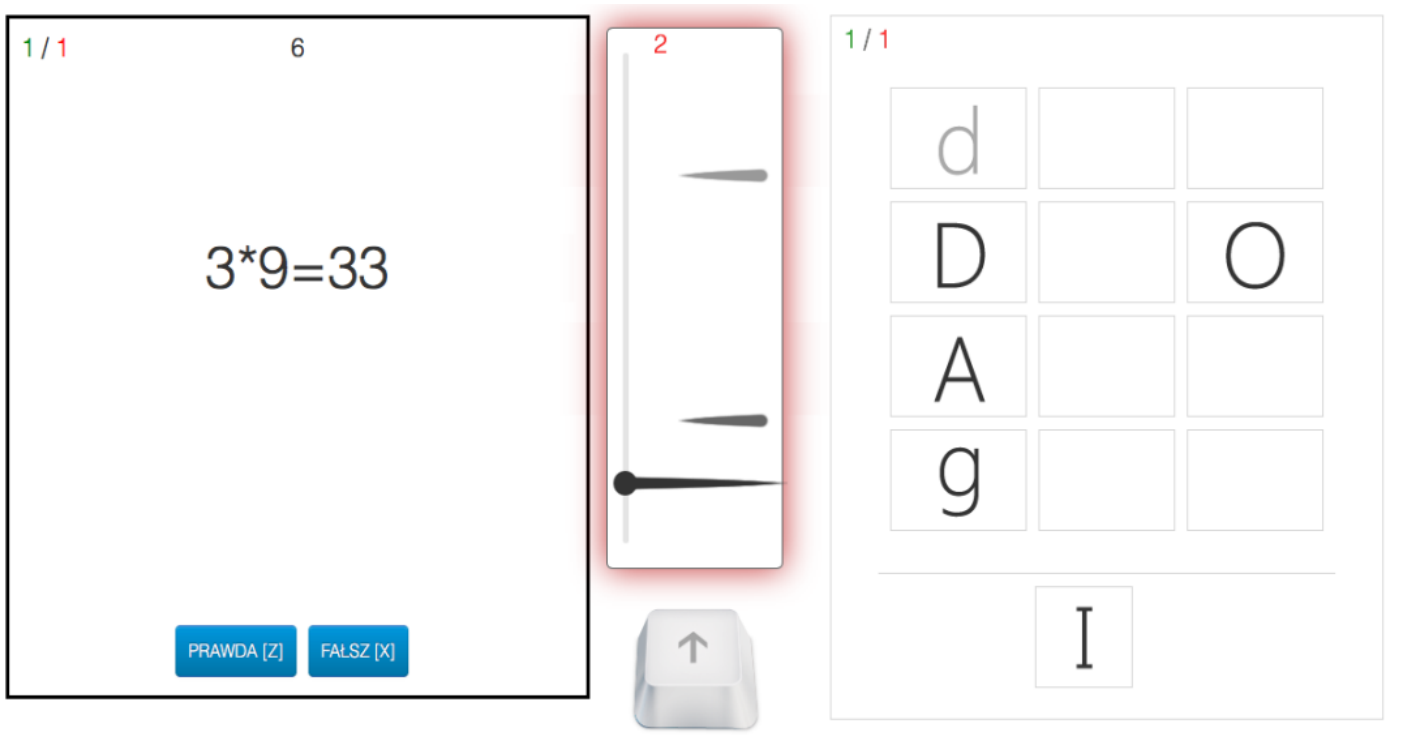

Figure 6. Screen shot from a task used in Study 4. In the figure, an error is signaled on the monitoring task (as indicated by the red background behind it) and the verification task is the currently "active" task (as indicated by the black frame around it). This means that currently the participant can react only in the verification task. After clicking on one of the other tasks, a black frame appears around that task, meaning that the participant could provide responses in the currently active task. 
Importance manipulation. We manipulated the importance of individual task goals by telling one group of participants that all tasks were equally important (control condition) and the other group that the mathematical task was the most important (increased importance condition). In each condition participants were told that the aim of the study was to test how people perform simultaneous tasks and that their aim was to perform three presented tasks as best as possible. To make monitoring progress on each task possible, the number of positive points for correct answers and negative points for incorrect answers were displayed on the screen. Importantly, in the increased importance condition, each correct response in the mathematical task was multiplied by 3 ; incorrect responses were multiplied by 2 . In the equal importance condition, payoff structure for correct and incorrect responses was the same for all tasks (participants were rewarded 1 point for correct and subtracted 1 point for incorrect response). Participants in this condition were still asked to perform all tasks and were rewarded with positive points for correct and negative points for incorrect responses in all three tasks.

Manipulation checks. After completing the multiple task procedure, participants were asked the following manipulation check questions: 1) How important was it for you to get the best score in the mathematical task? 2) How important was it for you to get the best score in the letter task? and 3) How important was it for you to get the best score in the monitoring task? Responses were given on a 7-point Likert scale (from not at all important to very important). Participants were also asked how often they switched between tasks (from $1=n o t$ at all to $7=$ very often) to see if the results obtained for the behavioral measure of switches corresponded to the reported frequency of switching. Participants who did not treat the mathematical task as important while in the increased importance condition (marked below the scale midpoint on the first question) were excluded from further analyses. 


\section{Procedure}

The study was run in a laboratory. After signing a consent form, participants were seated in front of computer screens and presented with the multiple-task procedure. They read the instructions and then went through the practice session, which was followed by the actual task. Before the actual task, participants read one of the two versions of the instructions: they were told either that all tasks were of equal importance (control condition) or that the mathematical task was the most important (increased importance condition). Participants were randomly assigned to one of the two conditions. After completing the task, participants responded to manipulation check questions and to the question about switching. They were then debriefed and thanked.

\section{Results}

The importance manipulation we used proved to be effective (see Supplementary Materials for more details). To test our main hypotheses, we checked the differences between the two importance conditions (our independent variable) in the number of switches between tasks (our dependent variable). Figure 7 presents a beanplot for the number of switches in the two conditions. On average, participants switched $M=100.19(S D=50.87)$ times in the control condition and $M=71.72(S D=56.94)$ times in the increased importance condition. Respective medians were 97 and 66.5. As in Studies 2 and 3, to test our hypotheses we analyzed the differences between medians (pb2gen function, WRS2 R package, Mair \& Wilcox, 2015). The results showed that the difference was statistically significant, diff. $=$ $30.50, p=.003,95 \% C I[-57.5,-11.5]$. Yuen's trimmed mean test with trimming level of $\gamma=$ 0.2 yielded similar results, $T_{y}(d f=110.17)=4.20, \mathrm{p}<.001$, with an effect size of $\xi=0.41$, $95 \%$ CI [0.22, 0.57].

We also checked whether the reported switches (the answer to the question after the study) followed the same pattern. We thus run a one-way ANOVA on the reported frequency 
of switching. The results showed a significant difference between conditions, $F(1,186)=$ $11.97, p<.001$, with participants in the control condition reporting significantly more frequent switching, $M=5.09(S D=1.8)$ than participants in the increased importance condition, $M=4.20(S D=1.76)$.

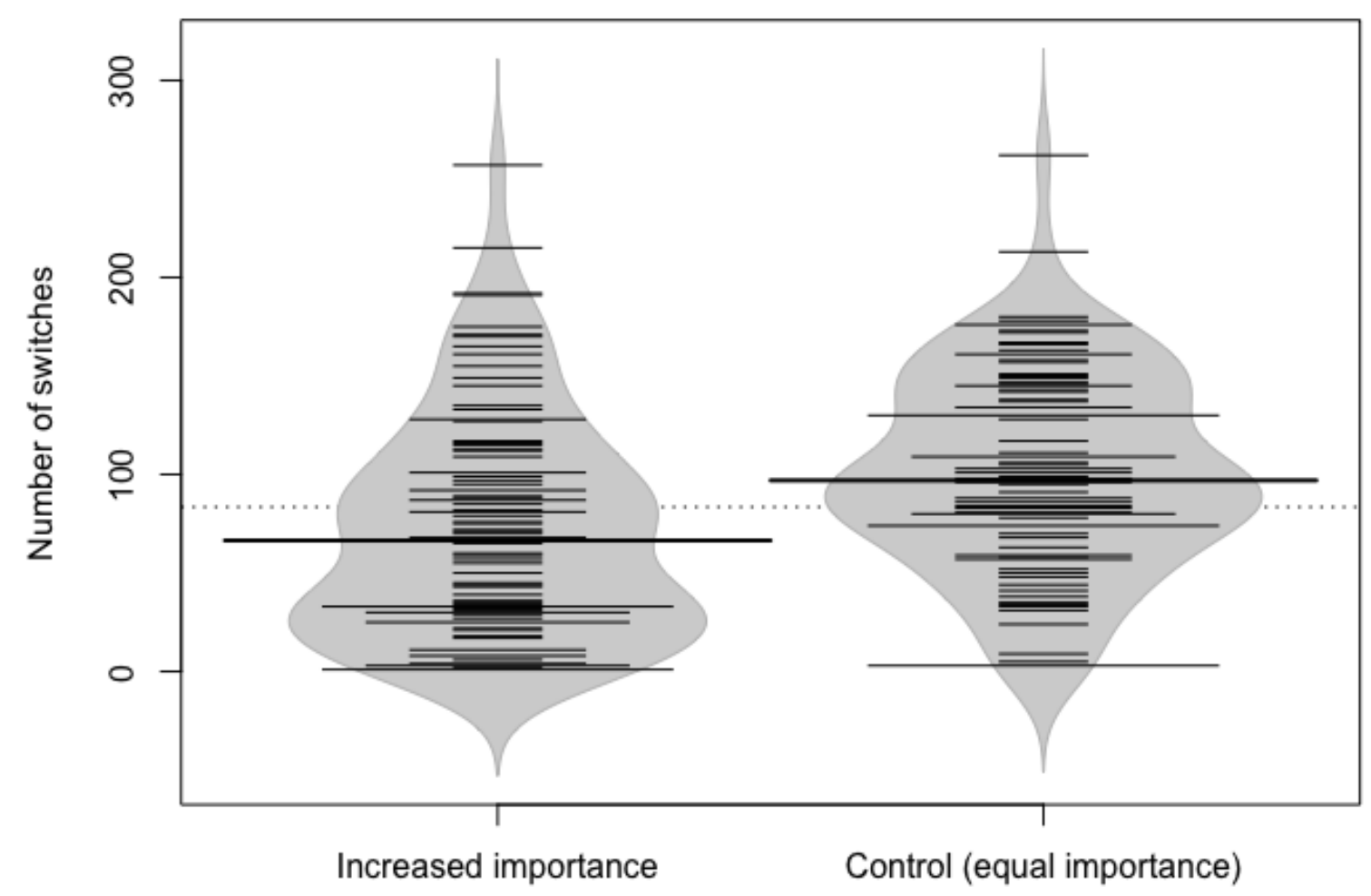

Figure 7. A beanplot for the number of switches between tasks in Study 4 for the control and increased importance conditions separately. Individual observations are represented as thin horizontal lines, the estimated density of the distributions is marked in grey and the thick lines represent the medians for the two groups.

\section{Discussion}

The results showed that even though participants had the same number of active task goals (all were asked to perform three tasks), the degree of multitasking differed depending on the condition. Participants in the equal importance (control) condition switched 
significantly more often than did participants in the increased importance condition. The results were significant for both the number of switches (behavioral measure) as well as the frequency of switches reported by participants. The study thus showed that increasing the importance of one of the active task goals decreases the degree of multitasking. Here, however, we used a very explicit manipulation of goal importance by telling participants that one of the tasks was more important than the others (we thus directly manipulated relative importance). In the next study, we wanted to check if a different manipulation of goal importance would affect multitasking in a similar way.

\section{Study 5}

The aim of this study was to further test whether increased importance of one of the active goals diminishes the degree of multitasking. Here, however, we wanted to use a less explicit manipulation of goal importance. Rather than experimentally created goals, we also wanted to use participants' own goals. Therefore, we used the same planning procedure as in Study 1 . We experimentally increased the importance of one of the goals via a mental contrasting procedure (Oetingen et al., 2001; Oetingen, 2000). We expected a lesser degree of multitasking in the increased importance condition compared to the control condition. The study was pre-registered. ${ }^{9}$

\section{Participants}

An a priori power analysis $\left(G^{*}\right.$ Power 3.1 , Faul et al., 2009) for a one-way ANOVA with two groups and a medium effect size $(f=.25)$ showed that a sample size of at least 128 would be necessary to obtain statistical power at the recommended level of .80. Therefore, in case of data loss, we recruited $169^{10}$ participants who were users of the Pollster research

\footnotetext{
${ }^{9}$ http://aspredicted.org/blind.php?x=gx7fe2

${ }^{10}$ We ordered data from 150 participants but obtained more from the research panel and decided to use all the data.
} 
platform. There were 102 women and 66 men aged $18-80(M=30.89, S D=7.06)$ with a minimum of high-school education. They were compensated for participation in the study based on the rates accepted by the platform. Only those participants who met our exclusion criteria (see the Materials and Procedure section) were included in final analyses. The final sample comprised $N=156$ participants (98 men, 58 women) with a mean of age of $M=30.62$ $(S D=7.18)$. The study was approved by the local Faculty Ethics Committee, and included informed consent from all the subjects.

\section{Materials and procedure}

In this study, we used the same procedure as in Study 1. Specifically, we asked participants to identify up to 10 tasks they perform in a typical day and then asked them to plan them in a calendar-like page. Participants were also instructed to split the tasks into separate blocks, plan them at the same time, or include overlaps if necessary to reflect multitasking. This time, however, instead of planning the rest of the day, participants were asked to plan their typical day and were presented with a calendar with hours from morning to evening (from 6 a.m. to 11 p.m.). Example plans created by participants in this study are presented in Figure 8. 


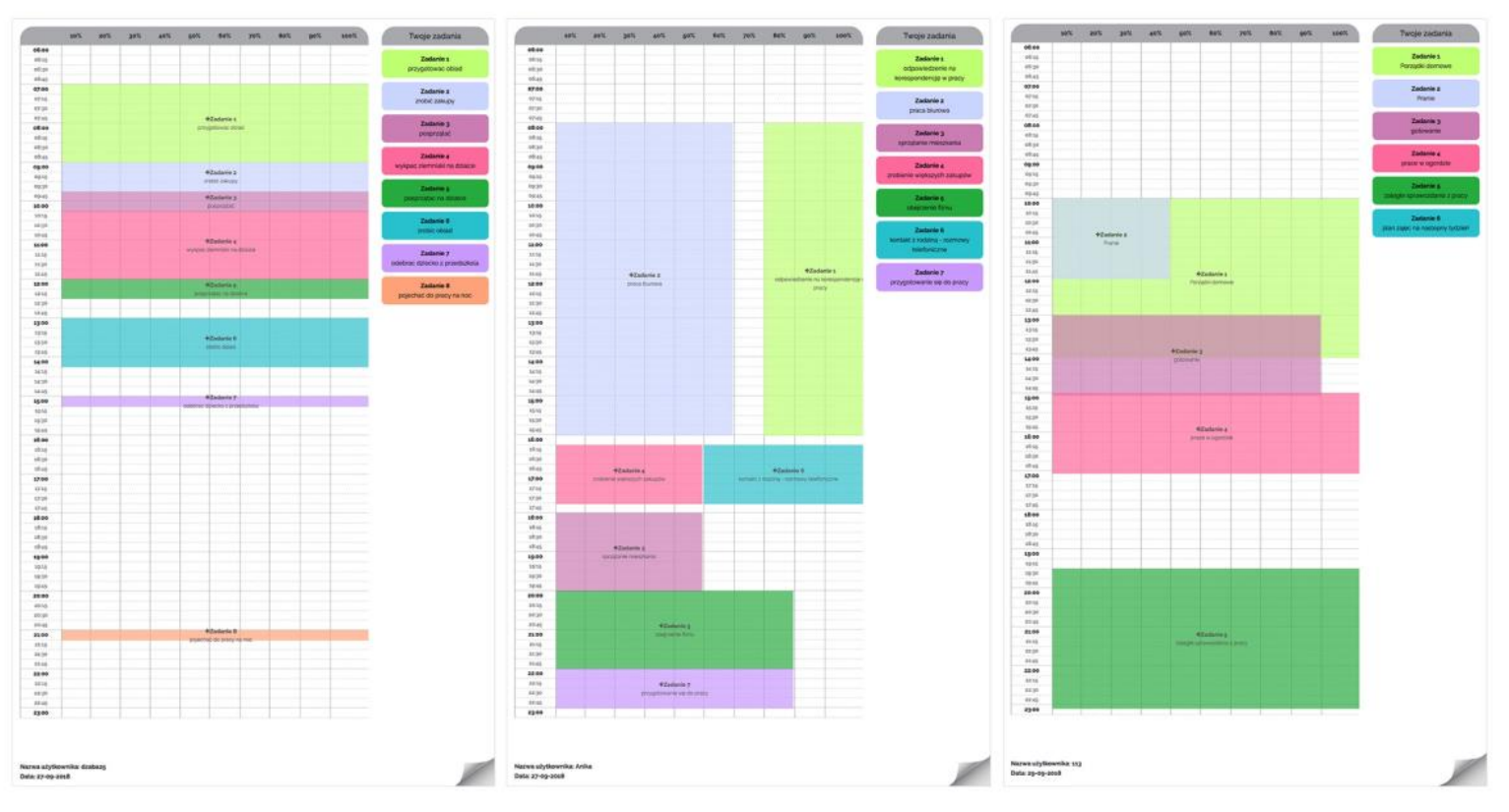

Figure 8. Example plans participants created in Study 5. The first plan involves no multitasking (presents a sequential strategy with no overlaps). In the second plan, there are four overlapping blocks. In the third plan, there are three overlapping blocks (overlaps are represented as a shared area in the plan, not as a block that is divided between 2 blocks).

Importantly, we also manipulated task importance in this study. We thus asked participants in the increased importance condition to select one of the tasks they had identified and indicate three advantages of completing this task. After they had done that, we asked them to identify three obstacles that could prevent them from completing this task. They thus underwent the mental contrasting procedure (Oetingen, 2000; Oetingen et al., 2001), which based on the assumption that contrasting the desirability of pursuit of a goal with the relevant obstacles would induce a state of cognitive dissonance - has often been found to increase goal importance (Kopetz et al., 2011; Oetingen et al., 2001). Participants in the control condition were also asked to indicate three advantages of completing one of the tasks they had 
identified in the first step. In the second step, however, instead of indicating obstacles, they were asked to indicate three advantages of completing another task they had identified.

After the manipulation, participants moved on to the planning task. There was no time limit. When they had completed the task, we asked them whether the task was clear to them (on a 1-7 scale from definitely unclear to definitely clear). Those who responded below the midpoint of the scale $(<4)$ were excluded from the analyses. Additionally, those who did not place any tasks in the calendar and those who did not provide meaningful answers to the manipulation questions were also excluded.

\section{Results}

On average participants identified $M=4.10(S D=2.39)$ tasks (ranging from 1 to 10$)$. As in Study 1, the number of identified tasks (activated goals) was correlated with various indices of multitasking performance (percentage-bend correlations were calculated with the WRS2 R package, Mair \& Wilcox, 2015). Particularly, the number of identified tasks was positively correlated with the number of overlapping blocks, $\rho_{\mathrm{pb}}=.29, p<.001$, and the amount of time two or more tasks overlapped in time (total duration of overlap), $\rho_{\mathrm{pb}}=.29, p<$ .001 . The latter two correlations were significant when percentage measures were tested instead of raw measures. Specifically, the more tasks were identified, the greater was the percentage of overlapping blocks (out of all blocks a participant created), $\rho_{\mathrm{pb}}=.25, p<.001$. Likewise, the more tasks were identified, the greater the percentage of time at least two tasks overlapped in time (out of the total time devoted to all tasks), $\rho_{\mathrm{pb}}=.27, p<.001$. The number of identified tasks also correlated negatively with the mean block duration, $\rho_{\mathrm{pb}}=-.21, p=$ .009. The results thus show that the more tasks a participant identified, the more likely they were to multitask. These results thus replicate the findings of Study 1 and 1B. 
In the present study, however, we were more interested in the difference between conditions. We thus ran Yuen's (1974) trimmed mean $t$-test ${ }^{11}$ (WRS2 R package, Mair \& Wilcox, 2015). Although we did not find significant effects for the total number of blocks or the average block duration (in both cases $T_{y}<1$ ), there was a significant difference in the number of overlapping blocks, $T_{y}(d f=48)=2.18, p=.034$. Trimmed means (with default trimming of .20), as well as non-trimmed means and standard deviations are presented in Table 2.

Table 2

Descriptive statistics for variables measured in Study $4(\mathrm{~N}=156)$

\begin{tabular}{lcccccc}
\hline & Control condition & \multicolumn{5}{c}{$\begin{array}{c}\text { Increased importance } \\
\text { condition }\end{array}$} \\
\hline & \multicolumn{7}{c}{$M$} & $S D$ & $M_{t}$ & $M$ & $S D$ & $M_{t}$ \\
\hline Total number of blocks & 4 & 2.29 & 3.98 & 4.16 & 2.35 & 4.17 \\
Mean block duration & 172.80 & 204.80 & 115.31 & 158.24 & 159.76 & 110.38 \\
Mean number of blocks & 1.10 & 0.28 & 1.01 & 1.11 & 0.59 & 1 \\
per task & & & & & & \\
Overlapping blocks [no.] & 0.80 & 1.34 & 0.37 & 0.64 & 1.44 & 0 \\
Overlapping blocks [\%] & 17.06 & 29.44 & 5.86 & 12.33 & 27.99 & 0 \\
Time of overlap [min.] & 37.97 & 112.55 & 3.67 & 34.68 & 116.53 & 0 \\
Time of overlap [\%] & 10.60 & 24.82 & 1.29 & 5.50 & 15.60 & 0 \\
\hline \multicolumn{1}{c}{ a $M$ - mean, SD - standard deviation, $M_{t}-$ trimmed mean. } &
\end{tabular}

A similar effect was also found for the percentage measure (i.e. the percentage of overlapping blocks out of all blocks created), as the difference between trimmed means was significant, $T_{y}(d f=48)=2.01, p<.050$. There was also a marginally significant difference for the overall time two or more tasks were performed at the same time (logged due to skewness of the data), $T_{y}(d f=48)=1.98, p=.053$. A similar result was obtained for the

\footnotetext{
${ }^{11}$ Due to non-normality of our data, instead of one-way ANOVA planned in our pre-registration protocol, we decided to use its robust equivalent.
} 
percentage measure (i.e., the percentage of time at least two tasks overlapped in time out of the total time devoted to all tasks $), T_{y}(d f=48)=1.80, p=.079$.

\section{Discussion}

The results of this study replicated the findings of Study 1 and 1B, showing that the more activated goals people have, the more likely they are to multitask. Importantly, however, they also showed that increased importance of one of the active goals decreases the likelihood of multitasking. In this experiment, participants who underwent the mental contrasting procedure (assumed to increase goal importance) had fewer overlapping blocks and budgeted less of their time to multitasking. These results are thus in line with the results of Study 4, which also showed a significant decrease in multitasking when the importance of one of the active goals was increased.

We should note, however, that the results we obtained in this study were weaker than the results of Study 4. We did not obtain significant results for all multitasking indices we used (e.g., mean block duration) and the difference between conditions, although significant, was not large. There might be several reasons for this. First, participants in this study identified fewer tasks (as compared to Study 1) but had more time available in their plans. This might have reduced the number of overlaps. Also, the manipulation was less explicit and our measures addressed planned multitasking rather than actual behavior. Despite these limitations, however, we found significant differences between conditions, which provides further support for the role of goal importance in multitasking.

\section{Study 6}

The aim of this study was to further test the relationship between goal importance and involvement in multitasking. However, instead of manipulating, we measured the importance of the primary goal and tested whether it was related to involvement in a secondary goal. In this study too we examined participants' everyday goals. Specifically, we focused on 
students' class-related goals (as primary goals). As secondary goals we selected those related to phone use. This selection was based on the growing literature showing that multitasking with phones and electronic devices in general is particularly prevalent, especially among the youth (Brown \& Cantor, 2000; Jacobsen \& Forste, 2011; Roberts, Foehr, \& Rideout, 2005; van Der Schuur, Baumgartner, Sumter, \& Valkenburg, 2015; Wood et al., 2012). Moreover, studies show that most of phone use during class serves other than class-related purposes with social purposes (as represented by texting, using social media, or emailing) being the most prevalent ones (Burns \& Lohenry, 2010; Junco, 2012; Junco \& Cotten, 2012) - and it is one of the major distractors from academic activities (Chen \& Yan, 2016; Grinols \& Rajesh, 2014). And even though smartphones can also be used to facilitate class participation and learning, studies show that when students have access to mobile phone during class, they most likely will engage in off-task multitasking too (e.g. Murphy \& Manzanares, 2008; Tindell \& Bohlander, 2012).

This is in line with what we have found in our pilot study in which we asked students to name activities they perform with their mobiles phones during class. Each participant was asked to name from 2 to 5 activities and rate to what extent this activity is related to the classgoal vs. some other goal and to what extent it hinders vs. helps their class participation. We then categorized these activities and summarized them in Table 2 in the Supplementary Materials. It turned out that there were almost twice as many activities related to other goals than those related to class (as per participants' ratings) and two most frequent categories participants indicated were related to other than class goals (i.e. "texting, messaging, contacting friends" and "checking social media"). Furthermore, even though participants differed in their in-class phone use, none of the participants used their phone in class solely for academic purposes. This is in line with findings that using mobile phones in class increases the degree of off-task multitasking (Murphy \& Manzanares, 2008; Tindell \& 
Bohlander, 2012). Therefore, we treated phone use during class as a good proxy of in-class multitasking. We expected that the higher importance of class-related goals would negatively predict multitasking represented as involvement in unrelated activity, such as phone use. The study was pre-registered. ${ }^{12}$

\section{Participants}

Based on the power analysis ${ }^{13}$ we recruited 138 University of Maryland students to participate in this online study in exchange for course credits. One hundred and thirty-one participants completed the study and only these participants were included in further analyses. There were 87 women and 44 men aged between 17 and $30(M=19.88, S D=1.89)$. Since all participants reported having a mobile phone and all identified 5 classes, we did not exclude any participants from the final analyses. The study was approved by the local Faculty Ethics Committee, and included informed consent from all participants (waiver of parental consent for participants aged 17 was obtained).

\section{Materials and Procedure}

Students were invited to participate in a survey on mobile phone use. They were first asked to identify five classes they were taking at the time of the study and then to answer several questions about each class. Specifically, they were asked: 1) How important is this class to you? 2) How important is this class to you relative to other classes? 3) How committed are you to the goal of getting a good grade in this class? 4) How difficult is this class for you? Responses were given on a 1-7 scale (from not at all to extremely). Reponses to the first three questions were averaged and treated as a measure of the importance of the

\footnotetext{
12 http://aspredicted.org/blind.php?x=e24qi9

${ }^{13}$ A power analysis for a mixed-model with the maximum random effect structure and a rather small fixed effect of -0.20 showed that a sample of at least 88 participants would be necessary to obtain power at .80 . Therefore, in case of any data loss, we strived to recruit about 100 participants. Since more participants took part in the study before it was closed, we decided to include all of them in the analyses. Power analysis was run with the simr $\mathrm{R}$ package (Green \& MacLeod, 2016).
} 
class-related goal (Cronbach $\alpha=.89$ ). Since participants might use their mobile phones because a class is too easy (and they are bored) or too difficult (and they are unable to follow it), the rating of class difficulty was included as a control variable.

After answering the above questions, participants progressed to the second part of the study, in which they were asked about their mobile phone use. Specifically, they were asked: 1) How likely are you to use your cell phone during each of the following classes? (on a 1-7 scale, from not at all likely to very likely), and 2) How often do you use your cell phone during each of the following classes? (on a 1-7 scale from never to always). Under each question the names of the classes they had listed in the first part of the study were presented and participants rated their phone use during each of them. Responses on the two items were averaged and treated as a measure of involvement in multitasking (Cronbach $\alpha=.83$ ). Results for the two items were also checked separately.

Apart from the above questions, participants were also asked whether they had a phone (and of what kind) and whether they had internet access on their device. At the end, demographic data were collected; participants were then debriefed and thanked for participation in the study.

\section{Results}

Descriptive statistics and intercorrelations between variables are presented in Table 3 .

Table 3

Descriptive statistics and correlations for variables measured in Study $6(\mathrm{~N}=131)$

\begin{tabular}{lcccccc}
\hline & $M$ & $S D$ & 1 & 2 & 3 & 4 \\
\hline Importance & 5.14 & 1.73 & & & & \\
Phone use likelihood & 3.35 & 2.05 & $-.15^{* * *}$ & & & \\
Phone use frequency & 3.08 & 1.87 & $-.15^{* * *}$ & $.72^{* * *}$ & & \\
Phone use index & 3.21 & 1.81 & $-.15^{* * *}$ & $.93^{* * *}$ & $.92 * * *$ & \\
Difficulty & 4.15 & 1.64 & $.42^{* * *}$ & $-.02^{* * *}$ & .00 & .00 \\
$* * * p<.001$ & & & & & &
\end{tabular}


Note: Phone use index was calculated by averaging phone use likelihood and frequency.

In line with our predictions, the importance of a given class was negatively related to both likelihood and frequency of mobile phone use. The results were similar for the aggregated measure (phone use index). However, to test our hypothesis properly, taking into account the hierarchical structure of our data, we ran a multi-level analysis in which we included classes as our lower-level data and participants as higher-level data. The analyses were run with the nlme R package (Pinheiro et al., 2018). We treated the importance of a class-related goal as our predictor variable and the averaged index of phone use as our dependent variable. The model included the maximum random effect structure justified by the data (Barr, Levy, Scheepers, \& Tilly, 2013; see Table 4 in the Supplementary Materials presenting the sequence of models we tested); however, we mainly focused on the fixed effect of class importance on phone use. Analyses were repeated including class difficulty as a control variable. Predictor variables were grand-mean centered.

Table 4 presents the results of the mixed model analyses. In line with our predictions, the importance of the class-related goal was negatively related to phone use in class (the effect is graphically presented in Figure 9). Including class difficulty as a statistical control did not alter the results (see Table 4). The results were also similar when reported phone use frequency and the likelihood of phone use in class were analyzed separately: for reported phone use frequency the effect was equal to $\mathrm{b}=-0.25, \mathrm{SE}=0.06, t=-4.15, p<.001$, and for phone use likelihood it was $\mathrm{b}=-0.22, \mathrm{SE}=0.07, t=-3.40, p<.001$. Also, the results did not change when we excluded 11 participants who did not have constant access to the Internet on their phone. The effect of class-related goal importance on phone use was, $b=-0.24, \mathrm{SE}=$ $0.06, t=-3.76, p<.001$. Additional regression analyses for each class separately are reported in Supplementary Materials. 
Table 4

Mixed-model results for Study $6(\mathrm{~N}=131)$

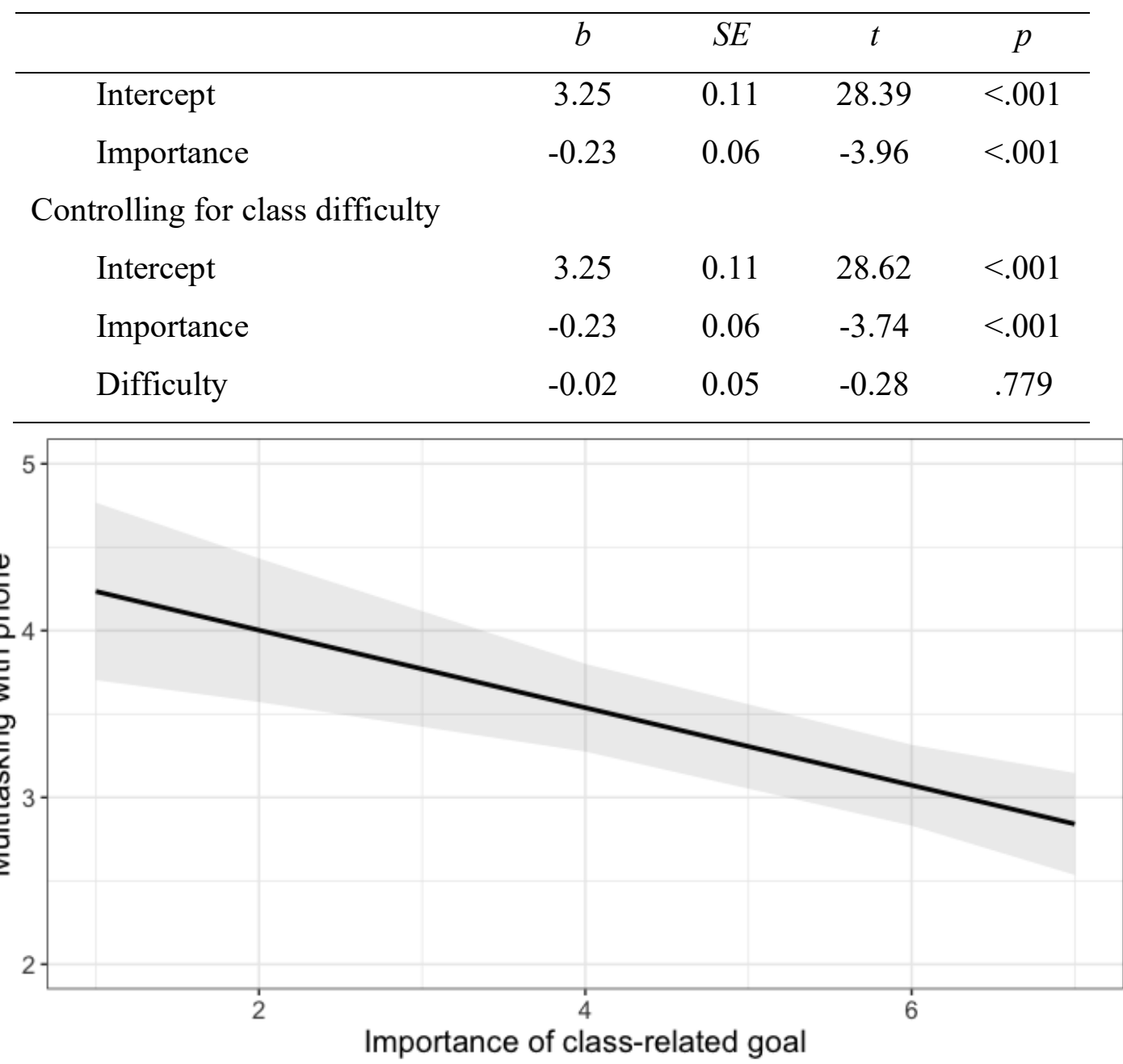

Figure 9. The relationship between the importance of a class-related goal and phone use in class. Confidence intervals are marked in grey.

\section{Discussion}

The results of the study showed that the greater the importance of a class-related goal, the lesser the likelihood of multitasking with a mobile phone. Thus, with different goals and utilizing a different study design, we provided further support for the hypothesis that the increased importance of one of the goals decreases multitasking. This shows that similar 
factors affect switching between tasks in the laboratory setting, participants' planning of everyday goals, and multitasking with electronic devices.

We should note, however, that although in this study we asked participants about their in-class phone use, we did not explicitly specify that the phone use should be unrelated to their class participation. Previous studies (e.g., Burns \& Lohenry, 2010; Murphy \& Manzanares, 2008; Tindell \& Bohlander, 2012) as well the results of our pilot study (see Supplementary Materials) indicate that most in-class phone use is related to other (mainly social) goals, therefore phone use can be treated as a proxy of in-class multitasking. Some of the reported phone use activity in our study, however, could be class-related. This may explain the variation in slopes for importance between participants: although everyone uses phone for purposes unrelated to class, some might do so (and use phone in relation to class) to a greater degree than others. Future studies could address these differences and study other factors that influence in-class multitasking (one candidate factor derived from our theory would be the importance of alternative, e.g., social, goals). Overall, however, the current study showed that there is a significant negative relationship between importance of classrelated goals and in-class multitasking. Similar effect in relation to everyday goals was found in another study (Study 6B, which for the sakes of economy of presentation is described in the Supplementary Materials) in which we measured importance of one of personal goals of our participants. Then, we asked them to name two other goals and asked about the likelihood of combing the task related to the main goal with alternative tasks and switching or dividing attention between the main and alterative tasks (i.e. we measured the likelihood of multitasking). The results are in line with the results of the current study in that they indicate that the greater the importance of the main task, the smaller the likelihood of multitasking (see Supplementary Materials for more details). 


\section{General discussion}

Despite the growing interest in human multitasking, still rather little is known about the conditions under which people are most likely to switch between unfinished tasks or engage in simultaneous task performance. In this paper, we have addressed this question by proposing that multitasking occurs when several of people's goals - each attached to different activities (means) - are activated. Though this proposition may appear to be simple and straightforward, on closer look it turns out to have unobvious implications deriving from a conception of goals and goal systems. First, all goals are capable of being activated or deactivated (inhibited). For multitasking to occur several goals must be concomitantly active. Relatedly, the activated goals must be of (near) equal importance. A situation in which one goal is appreciably more important than the others leads to suppression of the latter; in consequence multitasking is reduced.

Across six studies, we obtained support for this analysis. First, we demonstrated that the more active goals people have, the more likely they are to multitask. We also showed that the degree of multitasking is greatest when active goals are of equal importance and that increasing importance of one of the goals in the active set decreases multitasking. Specifically, we showed that the more active goals participants had, the more likely they were to plan their activities in a multitasking manner (Study 1, 1B \& 4) and to switch between tasks more often (Study 2). They also multitasked more under high (vs. low) interruption condition (Study 3). Further, we demonstrated that experimentally increasing the relative importance of one of the task goals (Study 4) or inducing greater commitment to a goal via a mental contrasting procedure (Study 5) significantly decreased the degree of multitasking. Study 6 additionally showed that the importance of a class-related goal at school negatively predicted media multitasking in class. 
Our findings suggest that both goal activation and goal importance play a crucial role in determining the degree of multitasking and as such add to the previous accounts of multitasking. The role of goal activation has been discussed in the "memory for goals" model of Altmann and Trafton (2002). However, the researchers focused mainly on goal suspension/resumption and the analysis of interruptions. A broader view has been proposed in Salvucci and Taatgen's (2011) theory of threaded cognition, however, the model is mainly focused on predicting and quantifying task interference. Both these frameworks are primarily concerned with the impact of multitasking on performance. In contrast, our model addresses the basic conditions underlying the initiation of multitasking and its rate, and highlights the role in these processes of the goals' relative magnitude and of goal activation. We discuss these issues more fully below.

\section{Goal activation}

The fact that the more active goals people have, the more likely they are to multitask can help explain why multitasking is more likely to occur in certain situations rather than others, e.g., a busy open-plan office (vs. a more traditional one, e.g., Heerwagen, Kampschroer, Powell, \& Loftness, 2004; Roper \& Juneja, 2008). Research shows that goals can be activated by situational and contextual cues (Higgins, 1996), not necessarily conscious ones (Bargh \& Ferguson, 2000; Heckhausen \& Beckmann, 1990). Therefore, in a stimulusrich context more goals can be activated at a given moment compared to a situation in which fewer environmental cues are present. This is especially the case when these cues have been repeatedly paired with certain goals in the past, thus acquiring the capability to cue them, in turn prompting multitasking (e.g., Meiran, 1996; Monsell, 2003; Kruglanski \& Szumowska, 2020).

These notions are consistent with the extensive literature on the effects of interruptions (e.g., Gonzales \& Mark, 2004; Iqbal \& Horvitz, 2007; McFarlane \& Latorella, 2002; Monk et 
al., 2008). Interruptions from external cues (e.g., an incoming phone call, electronic alert or email notification), break one's focus on a current task and invite switching to another activity (e.g., Law, Logie, Pearson, et al., 2002). Interruptions do not have to be externally triggered and can also be internally-motivated (constituting the so called 'self-interruptions', e.g., Adler \& Benbunan-Fich, 2013). In this vein, our studies show that merely asking participants to name the tasks they need to perform increases the degree of multitasking.

Goal activation also helps understand the increase of multitasking which accompanies the growing popularity of new technologies and electronic devices (Cardoso-Leite, Green, \& Bavelier, 2015; Courage et al., 2015; Ophir, Nass, \& Wagner, 2009). The latest technologies (e.g., smartphones), unlike the more traditional ones (regular phones), are getting more and more multifinal: They are capable of performing multiple functions and hence serving a variety of different goals (e.g., calling, texting, instant messaging, writing emails, taking photos etc.). Since goals and means are interconnected (Kruglanski et al., 2002, 2015), activation of a goal can activate the means and vice versa (Shah \& Kruglanski, 2003). Accordingly, a multifinal device can activate several goals at the same time. So even when used for one specific goal (answering a call), it can subsequently activate other goals (e.g., checking social media) which were not active in the first place. Adding to this the ease of switching and the numerous notification alerts that might act as interrupters makes multitasking almost inevitable.

Our studies also help understand why multitasking increases when people have more tasks to do. Importantly, however, this is not the mere presence of more tasks that is responsible for engagement in multitasking, but rather the activation of these tasks/goals. One can imagine two people having the same set of tasks to complete within a given time period. One person, however, can be mindful of all these tasks for the whole time, whereas the other can prioritize one task at a time, thus focusing only on one (and inhibiting the rest). These 
differences in the number of active goals (rather than the total number of tasks to complete) would translate into differences in strategies adopted by the two individuals: the former will be more likely to multitask, whereas the latter will be more likely to adopt a sequential strategy of task completion.

\section{Goal importance}

The finding that (all else being equal) multitasking decreases when one of the tasks becomes more important is relevant to a variety of situations. Goal importance can be determined by different factors such as the goal's subjective value (Atkinson \& Birch, 1970; Lewin, Dembo, Festinger, \& Sears, 1944; Vancouver, Weinhardt, \& Schmidt, 2010), participant's current needs and motivational states, the situation one is in, and the sense of urgency, or the need to act upon the goal (Vancouver et al., 2010) often signaled by affect (Carver \& Scheier, 2009; Simon, 1967). Via increasing or decreasing goal importance, a change in any of these elements can also affect the degree of multitasking.

This way of thinking is in line with research positing that people utilize two basic strategies of goal pursuit: balancing between goals or highlighting the most important goal (Fishbach, 2009; Vallerand, 2015; Kruglanski, Szumowska, Kopetz, Vallerand \& Pierro, 2020). Our studies show that when multiple goals are activated and the need for balancing is induced, people indeed switch between tasks more often. When the importance of a given goal is increased (one of the goals is highlighted), switching or balancing tendencies diminish.

Our results suggest is this is the relative importance of the goals, rather than their absolute importance that matters. In other words, people will switch between tasks as long as the active goals are of equal importance, either high or low. Only when importance of one of the tasks increases relative to others, the rate of switching will decrease. This has an unobvious implication that people who have several very important goals, all of which are equally important, will devote less time and resources to these goals in a given time block, the 
more of them are currently active. That is, absolute importance of the goals will not translate into more time and resources devoted to them in a given time block, as would be the case in a single goal scenario. Moreover, when we increase the importance of all goals equally (thus increasing the "total task motivation", all else being equal), the rate of switching will not be affected. So it is one goal's priority over others, rather than overall motivation, that matters for switching.

This is also in line with a broader work on motivational (im)balance (e.g., Kruglanski et al., 2020; Kruglanski, Fernandez, Factor, \& Szumowska, 2019). Extensive research shows that under a state of motivational imbalance - when one goal is considerably more important than the others - people neglect other goals for the sake of the main, focal goal, which enables extreme behavior of various sorts (see review in Kruglanski et al., 2020). In other words, rather than switching to other goals people persist in pursuing the one goal that matters the most. In some cases this dynamic might lead to a variety of negative consequences (as is the case in violent extremism, addictions, or obsessive pursuit of one goal). Our studies add to this picture by showing that equal importance of goals, or motivational balance, does indeed foster switching between goals, thus keeping multiple concerns within their region of satisfaction.

\section{Goal-systemic boundary conditions}

As noted earlier, research by Kopetz et al. (2011) found that when people have multiple active goals to pursue, they are more likely to select multifinal means which would allow them to satisfy all currently active goals. Similarly, Orehek and Vazeou-Nieuwenhuis (2013) have argued that people use either a sequential strategy of goal pursuit addressing one goal at a time, or a concurrent goal pursuit based on the multifinality principle (Chun \& Kruglanski, 2005; Chun, Kruglanski, Sleeth-Keppler, \& Friedman, 2011; Kopetz et al., 2011; Kruglanski, Kopetz, Belanger, Chun, Orehek \& Fishbach, 2012; Kruglanski et al., 2002). It is thus likely 
that where multifinal means are available, individuals may not need to multitask. Indeed, in our definition of multitasking we specified that it happens when people have several active goals, each attached to a different activity (task). Hence, when people could satisfy several goals by performing only one multifinal activity, multitasking would not be necessary.

\section{Limitations and future research directions}

In studies presented in this paper, we have shown that when one goal is more important than others, multitasking is less likely to happen as compared to a situation in which the goals are of approximately equal importance. Of course, goals' relative magnitude is a quantitative dimension. The degree to which a given goal exceeds the others in its magnitude lies on a continuum. Presumably then, the tendency to engage in multitasking should vary monotonically as function of such degree. This proposition could be profitably explored in subsequent research.

Individual differences, too, should determine the degree of multitasking. For instance, need for closure (Kruglanski, 1990), a variable related to the filtering out of distractors and increasing commitment to the focal goal (Kossowska, 2007; Szumowska \& Kossowska, 2017) should be related inversely to multitasking. Indeed, previous studies have shown that high-need-for-closure individuals are less likely to engage in multitasking and switch less often between tasks in a multiple task procedure (Szumowska, Popławska-Boruc, \& Kossowska, 2018; unless multitasking is required by the task rules, see Szumowska, Kossowska, \& Roets, 2018). On the other hand, frequent media multitasking, or involvement in simultaneous media use, has been linked to greater distractibility and inability to inhibit external stimuli (e.g., Ophir et al., 2009). These initial findings show that not only the situation but also individual differences can affect the number of active goals one juggles at a given moment. Individual differences and chronic motives might also have an effect on the degree of multitasking via increasing/decreasing the importance of given goals. Some task 
specific (e.g. performing well on a math exam) or non-specific motivations (e.g., perfectionism, achievement, or closure motivation) can influence importance of given tasks (relative to other tasks). As a result, given the same set of active goals, one person can switch more often than another person in the same situation. It would be useful to explore this issue in future studies.

We have argued that activation of multiple goals promotes multitasking and switching. Sometimes, however, people adopt strategies that can modify their switching behavior. For instance, they might decide not to switch even when they feel the urge to do so. This can be achieved either by effortful control (goal inhibition) as well as by some external strategies (using computer applications that control and minimize interruptions, Bailey \& Konstan, 2006; McFarlane \& Latorella, 2002; Szumowska et al., 2018). We think it likely that success of such strategies would be related to the extent to which they limit the number of active goals (as in case of interruption controlling apps) or increase relative the importance of one of the tasks in an active set (Zhang \& Fishbach, 2010, argue for instance that people employ strategies which increase the importance of a given goal and decrease the strength of interfering alternatives in order to shield that goal from distraction). The influence of such regulatory strategies on involvement in multitasking should be tested in further studies.

An important issue for further examination is the generalizability of the present results. Across diverse samples (Polish - Studies 1-5 and American - Study 6) and studies we obtained consistent effects for different laboratory tasks (Study 2, 3 \& 4), participants' everyday goals (Studies 1A, 1B \& 5), and media multitasking (Study 6). We thus assume that the same factors - goal activation and goal importance - influence multitasking with different task types and at different levels. Further studies, possibly in naturalistic settings are required to test these effects on an even wider variety of tasks and situations. 


\section{Conclusions}

In the current paper we addressed the quintessential question of when do people multitask. Across six studies, we have shown that the degree of multitasking increases with the number of active goals and decreases with the increasing importance of one of the goals relative to the others. These findings point to the relevance of goals' psychological properties and those of multiple-goals systems to the phenomenon of multitasking thus illuminating this common behavior from a broader motivational perspective.

\section{Context}

This paper addresses the question "What determines the extent to which people engage in multitasking". Our results suggest that the degree of multitasking is determined by the number of equally important active goals. Multitasking is diminished when the number of one's active goals shrinks, and when a given dominant goal crowds out other active goals. In addressing the present research question of interest, this paper thus integrates the domain of multitasking research with that of multiple goal pursuit, and highlights their fundamental relevance to each other. 


\section{References}

Adler, R. F., \& Benbunan-Fich, R. (2012). Juggling on a high wire: Multitasking effects on performance. International Journal of Human-Computer Studies, 70(2), 156-168.

Adler, R. F., \& Benbunan-Fich, R. (2013). Self-interruptions in discretionary multitasking. Computers in Human Behavior, 29, 1441-1449.

Altmann, E. M., \& Trafton, J. G. (2002). Memory for goals: An activation-based model. Cognitive Science, 26, 39-83.

Atkinson, J. W., \& Birch, D. (1970). The dynamics of action. New York, NY: Wiley.

Bailey, B. P., \& Konstan, J. A. (2006). On the need for attention-aware systems: Measuring effects of interruption on task performance, error rate, and affective state. Computers in Human Behavior, 22, 685-708.

Banbury, S., \& Berry, D. C. (1998). Disruption of office-related tasks by speech and office noise. British journal of psychology, 89(3), 499-517.

Bargh, J. A. (1990). Auto-motives: Preconscious determinants of social interaction. In E. T. Higgins \& R. M. Sorrentino (Eds.), Handbook of motivation and cognition (Vol. 2, pp. 93-130). New York, NY: Guilford Press.

Bargh, J. A., \& Ferguson, M. J. (2000). Beyond behaviorism: On the automaticity of higher mental processes. Psychological Bulletin, 126, 925-945.

Barr, D.J., Levy, R., Scheepers, C., \& Tilly, H. J. (2013). Random effects structure for confirmatory hypothesis testing: Keep it maximal. Journal of Memory and Language, $68,255-278$.

Bedny, G. Z., Seglin, M. H., \& Meister, D. (2000). Activity Theory: History, research and application. Theoretical Issues in Ergonomics Science, 1(2), 168-206.

Bluedorn, A. C., \& Jaussi, K. S. (2007). Organizationally relevant dimensions of time across levels of analysis. Research in Multi-Level Issues, 6, 187-223. 
Bluedorn, A.C., Kalliath, T.J., Strube, M.J, \& Martin, G.D. (1999). Polychronicity and the Inventory of Polychronic Values (IPV). The development of an instrument to measure a fundamental dimension of organizational culture. Journal of Managerial Psychology, $14,205-230$.

Bluedorn, A. C., Kaufman, C. F., \& Lane, P. M. (1992). How many things do you like to do at once? An introduction to monochronic and polychronic time. Academy of Management Executive, 6, 17-26.

Brown, J. D., \& Cantor, J. (2000). An agenda for research on youth and the media. Journal of Adolescent Health, 27, 2-7.

Brumby, D. P., Salvucci, D. D., \& Howes, A. (2009, April). Focus on driving: How cognitive constraints shape the adaptation of strategy when dialing while driving. In Proceedings of the SIGCHI Conference on Human Factors in Computing Systems (pp. 1629-1638). New York: ACM.

Buhner, M., Konig, C. J., Pick, M., \& Krumm, S. (2006). Working Memory Dimensions as Differential Predictors of the Speed and Error Aspect of Multitasking Performance. Human Performance, 19, 253-275.

Burgess, P. W. (2000). Strategy application disorder: The role of the frontal lobes in human multitasking. Psychological Research, 63, 279-288.

Burns, S. M., \& Lohenry, K. (2010). Cellular phone use in class: Implications for teaching and learning a pilot study. College Student Journal, 44(3), 805-811.

Cantor, N., \& Langston, C. A. (1989). Ups and downs of life tasks in a life transition. In L. A. Pervin (Ed.), Goal concepts in personality and social psychology (pp. 127-167). Hillsdale, NJ: Erlbaum.

Cardoso-Leite, P., Green, C. S., \& Bavelier, D. (2015). On the impact of new technologies on multitasking. Developmental Review, 35, 98-112. 
Carver, C. S., \& Scheier, M. F. (1998). On the self-regulation of behavior. New York, NY: Cambridge University Press

Carver, C. S. \& Scheier, M. F. (2009). Action, Affect, Multitasking, and Layers of Control. In J. P. Forgas, R. F. Baumeister, and D. M. Tice (Eds.), Psychology of Self-Regulation: Cognitive, Affective, and Motivational Processes (pp. 109-126). New York: Psychology Press.

Carrier, L. M., Rosen, L. D., Cheever, N. A., \& Lim, A. F. (2015). Causes, effects, and practicalities of everyday multitasking. Developmental Review, 35, 64-78.

Carver, C. S. (2004). Self-regulation of action and affect. In R. F. Baumeister \& K. D. Vohs (Eds.), Handbook of self-regulation: Research, theory, and applications (pp. 13-39). New York, NY: Guilford Press.

Carver, C. S., \& Scheier, M. F. (1998). On the self-regulation of behavior. New York: Cambridge University Press.

Cascio, W. (1978). Applied psychology in personnel management. Reston, VA: Reston Publishing.

Chen, Q., \& Yan, Z. (2016). Does multitasking with mobile phones affect learning? A review. Computers in Human Behavior, 54, 34-42.

Chun, W. Y., \& Kruglanski, A. W. (2005). Kill Two Birds with One Soap: the Multifinality Pursuit and the Need for Closure. Asia Pacific Advances in Consumer Research, 6, 261.

Chun, W., \& Kruglanski, A. (2005). Consumption as a multiple-goal pursuit without Awareness. In F. R. Kardes, P. M. Herr, \& J. Nantel (Eds.), Applying social cognition to consumer-focused strategy (pp. 201-217). Mahwah, NJ: Erlbaum Publishers.

Chun, W., Kruglanski, A. W., Sleeth-Keppler, D., \& Friedman, R. (2011). Multifinality in implicit choice. Journal of Personality and Social Psychology, 101, 1124-1137 
Cohen, J. (1988). Statistical power analysis for the behavioral sciences (2nd ed.). Hillsdale, NJ: Erlbaum.

Colom, R., Martínez-Molina, A., Shih, P. C., \& Santacreu, J. (2010). Intelligence, working memory, and multitasking performance. Intelligence, 38, 543-551.

Cotte, J. \& Ratneshwar, S. (1999). Juggling and hopping: what does it mean to work polychronically? Journal of Managerial Psychology, 14, 184-204.

Courage, M. L., Bakhtiar, A., Fitzpatrick, C., Kenny, S., \& Brandeau, K. (2015). Growing up multitasking: The costs and benefits for cognitive development. Developmental Review, $35,5-41$.

Czerwinski, M., Horvitz, E., \& Wilhite, S. (2004, April). A diary study of task switching and interruptions. In Proceedings of the SIGCHI Conference on Human Factors in Computing Systems (pp. 175-182).

De Houwer, J. (2019). On How Definitions of Habits Can Complicate Habit Research. Frontiers in Psychology, 10:2642.

Dobbs, S., Furnham, A., \& McClelland, A. (2011). The effect of background music and noise on the cognitive test performance of introverts and extraverts. Applied Cognitive Psychology, 25, 307-313.

Drews, F. A. \& Musters, A. (2015). Individual differences in interrupted task performance: One size does not fit all. International Journal of Human-Computer Studies, 79, 97-105. Emmons, R. A., King, L. A., \& Sheldon, K. (1993). Goal conflict and the self-regulation of action. In D. M. Wegner \& J. W. Pennebaker (Eds.) Handbook of mental control (pp. 528-551). Englewood Cliffs, NJ: Prentice-Hall.

Farmer, G.D., Janssen, C. P., Nguyen, A. T., \& Brumby, D. P. (2017). Dividing Attention Between Tasks: Testing Whether Explicit Payoff Functions Elicit Optimal Dual-Task Performance. Cognitive Science, 42, 820-849. 
Faul, F., Erdfelder, E., Buchner, A., and Lang, A. G. (2009). Statistical power analyses using G* Power 3.1: Tests for correlation and regression analyses. Behavior Research Methods, 41, 1149-1160.

Fishbach, A. (2009). The Dynamics of Self-Regulation. In J. P. Forgas, R. F. Baumeister, and D. M. Tice (Eds.), Psychology of Self-Regulation: Cognitive, Affective, and Motivational Processes (pp. 163-181). New York: Psychology Press.

Fishbach, A., \& Dhar, R. (2007). Dynamics of goal-based choice. In C. P. Haugtvedt, P. M. Herr, \& F. R. Kardes (Eds.), Hand- book of consumer psychology (pp. 611-637). New York: Psychology Press.

Fitzsimons, G. M., Friesen, J., Orehek, E., \& Kruglanski, A. W. (2009). Progress-Induced Goal Shifting as a Self-Regulatory Strategy. In J. P. Forgas, R. F. Baumeister, and D. M. Tice (Eds.), Psychology of Self-Regulation: Cognitive, Affective, and Motivational Processes (pp. 183-197). New York: Psychology Press.

Forster, J., Liberman, N., \& Higgins, E. T. (2005). Accessibility from active and fulfilled goals. Journal of Experimental Social Psychology, 41(3), 220-239.

Gillie, T., \& Broadbent, D. E. (1989). What makes interruptions disruptive? A study of length, similarity, and complexity. Psychological Research, 50, 243-250.

Gollwitzer, P. M., \& Moskowitz, G. B. (1996). Goal effects on action and cognition. In E. T. Higgins \& A. W. Kruglanski (Eds.), Social psychology: Handbook of basic principles (pp. 361-399). New York: Guilford Press.

Gonzalez, V. M., \& Mark, G. (2004). “Constant, constant, multi-tasking craziness”: Managing multiple working spheres. In Proceedings of CHI 2007 (pp. 113-120). New York: ACM.

Green, P., \& MacLeod, C. J. (2016). “simr: an R package for power analysis of generalised linear mixed models by simulation.” Methods in Ecology and Evolution, 7(4), 493-498. 
Grinols, A. B., \& Rajesh, R. (2014). Multitasking with smartphones in the college classroom. Business and Professional Communication Quarterly, 77(1), 89-95.

Hall, E. T., \& Hall, M. R. (1990). Understanding Cultural Differences: Germans, French and Americans. Yarmouth, ME: Intercultural Press.

Hambrick, D. Z., Oswald, F. L., Darowski, E. S., Rench, T. A., \& Brou, R. (2010). Predictors of Multitasking Performance in a Synthetic Work Paradigm. Applied Cognitive Psychology, 24, 1149-1167.

Hannah, S. D., \& Neal, A. (2014). On-the-fly scheduling as a manifestation of partial-order planning and dynamic task values. Human Factors, 56, 1093-1112.

Heckhausen, H., \& Beckmann, J. (1990). Intentional action and action slips. Psychological Review, 97, 36-48.

Heerwagen, J. H., Kampschroer, K., Powell, K. M., \& Loftness, V. (2004). Collaborative knowledge work environments. Building Research \& Information, 32(6), 510-528.

Higgins, E. T. (1996). Knowledge activation: Accessibility, applicability, and salience. In E. T. Higgins \& A. W. Krugianski (Eds.), Social psychology: Handbook of basic principles (pp. 133-168). New York: Guilford Press.

Hull, C. L. (1938). The goal-gradient hypothesis applied to some "fieldforce" problems in the behavior of young children. Psychological Review, 45, 271-299.

Iqbal, S. T., \& Bailey, B. P. (2005). Investigating the effectiveness of mental workload as a predictor of opportune moments for interruption. In $\mathrm{CHI}^{\prime} 05$ extended abstracts on Human factors in computing systems (pp. 1489-1492). New York: ACM.

Iqbal, S. T., \& Horvitz, E. (2007). Disruption and recovery of computing tasks: Field study, analysis, and directions. In Proceedings of CHI 2007 (pp. 677-686). New York: ACM.

Ishizaka, K., Marshall, S. P., \& Conte, J. M. (2001). Individual differences in attentional strategies in multitasking situations. Human Performance, 14, 339-358. 
Jacobsen, W. C., \& Forste, R. (2011). The wired generation: Academic and social outcomes of electronic media use among university students. Cyberpsychology, Behavior, and Social Networking, 14, 275-280.

Janssen, C. P., \& Brumby, D. P. (2010). Strategic adaptation to performance objectives in a dual-task setting. Cognitive Science, 34(8), 1548-1560.

Janssen, C. P., Brumby, D. P., \& Garnett, R. (2012). Natural break points: The influence of priorities, and cognitive and motor cues on dual-task interleaving. Journal of Cognitive Engineering and Decision Making, 6(1), 5-29.

Janssen, C. P., Gould, S. J., Li, S., Brumby, D. P., \& Cox, A. L. (2015). Integrating knowledge of multitasking and Interruptions across different perspectives and research methods. International Journal of Human-Computer Studies, 79, 1-5.

Jersild, A. T. (1927). Mental set and shift. Archives of Psychology, 14 (Whole No. 89).

Junco, R. (2012). In-class multitasking and academic performance. Computers in Human Behavior, 28(6), 2236-2243.

Junco, R., \& Cotten, S. R. (2012). No A 4 U: The relationship between multitasking and academic performance. Computers \& Education, 59(2), 505-514.

Kampstra, P. (2008). Beanplot: A Boxplot Alternative for Visual Comparison of Distributions. Journal of Statistical Software, Code Snippets, 28(1), 1-9.

Kampstra, P. (2014). Beanplot: A Boxplot Alternative for Visual Comparison of Distributions. Retrieved from https://CRAN.R-project.org/package=beanplot.

Kc, D. S. (2014). Does multitasking improve performance? Evidence from the emergency department. Manufacturing \& Service Operations Management, 16(2), 168-183.

Kleinsorge, T., \& Scheil, J. (2015). Effects of reducing the number of candidate tasks in voluntary task switching. Frontiers in Psychology, 5, 1555. 
Kliegel, M., Jager, T., \& Phillips, L. H. (2008). Adult age differences in event-based prospective memory: A meta-analysis on the role of focal versus nonfocal cues. Psychology \& Aging, 23(1), 203-208.

Konig, C. J., Oberacher, L., \& Kleinmann, M. (2010). Personal and situational determinants of multitasking at work. Journal of Personnel Psychology, 9(2), 99-103.

Konig, C. J., \& Waller, M. J. (2010). Time for reflection: A critical examination of polychronicity. Human Performance, 23(2), 173-190.

Kopetz, C., Faber, T., Fishbach, A., \& Kruglanski, A. W. (2011). The multifinality constraints effect: How goal multiplicity narrows the means set to a focal end. Journal of Personality and Social Psychology, 100(5), 810-826.

Kossowska, M. (2007). The role of cognitive inhibition in motivation toward closure. Personality and Individual Differences, 42, 1117-1126.

Kruglanski, A. W. (1990). Lay epistemic theory in social-cognitive psychology. Psychological Inquiry, 3, 181-197.

Kruglanski, A. W. (1996). Goals as knowledge structures. In P. M. Gollwitzer \& J. A. Bargh (Eds.), The psychology of action: Linking cognition and motivation to behavior (pp. 599-618). New York, NY: Guilford Press.

Kruglanski, A. W., Bélanger, J. J., Chen, X., Köpetz, C., Pierro, A., \& Mannetti, L. (2012). The energetics of motivated cognition: A force-field analysis. Psychological Review, 119(1), 1-20.

Kruglanski, A. W., Chernikova, M., Babush, M., Dugas, M., \& Schumpe, B. M. (2015). The Architecture of Goal Systems: Multifinality, Equifinality, and Counterfinality in MeansEnd Relations. Advances in Motivation Science, 2, 69-98.

Kruglanski, A. W., Chernikova, M., Rosenzweig, E., \& Kopetz, C. (2014). On motivational readiness. Psychological Review, 121, 367-388. 
Kruglanski, A. W., Fernandez, J. R., Factor, A. R., \& Szumowska, E. (2018). Cognitive mechanisms in violent extremism. Cognition, 188, 116-123.

Kruglanski, A. W., \& Kopetz, C. (2009). What is so special (and nonspecial) about goals? A view from the cognitive perspective. In G. B. Moskowitz \& H. Grant (Eds.), The psychology of goals (pp. 27-55). Guilford.

Kruglanski, A. W., Kopetz, C., Bélanger, J. J., Chun, W. Y., Orehek, E., \& Fishbach, A. (2013). Features of multifinality. Personality and Social Psychology Review, 17(1), 2239.

Kruglanski, A. W., Shah, J. Y., Fishbach, A., Friedman, R., Chun, W. Y., \& Sleeth-Keppler, D. (2002). A Theory of Goal Systems. Advances in Experimental Social Psychology, $34,331-378$.

Kruglanski, A. W., \& Szumowska, E. (2020). Habitual behavior is goal-driven. Perspectives on Psychological Science, 15(5), 1256-1271.

Kruglanski, A. W., Szumowska, E., Kopetz, C. H., Vallerand, R. J., \& Pierro, A. (2020). On the Psychology of Extremism: How Motivational Imbalance Breeds Intemperance. Psychological Review. Article in press.

Kruglanski, A. W. \& Webster, D. M. (1996). Motivated closing of the mind: "seizing" and “freezing." Psychological Review, 103, 263-283.

Law, A. S., Logie, R. H., \& Pearson, D. G. (2006). The impact of secondary tasks on multitasking in a virtual environment. Acta Psychologica, 122(1), 27-44.

Law, A. S., Logie, R. H., Pearson, D. G., Cantagallo, A., Moretti, E., \& Dimarco, F. (2002). Resistance to the impact of interruptions during multitasking by healthy adults and dysexecutive patients. Acta Psychologica, 116, 285-307.

Lewin, K. (1951). Field theory in social sciences. New York, NY: Harper. 
Lewin, K., Dembo, T., Festinger, L., \& Sears, P. S. (1944). Level of aspiration. In J. McV. Hunt (Ed.), Personality and behavior disorders (pp. 333-378). New York: Ronald.

Louro, M. J., Pieters, R., Zeelenberg, M. (2007). Dynamics of multiple-goal pursuit. Journal of Personality and Social Psychology, 93, 174-93.

Luh, W. M., Olejnik, S., \& Guo, J. H. (2008). Sample size determination for one-and twosample trimmed mean tests. The Journal of Experimental Education, 77(2), 167-184.

Mair, P., \& Wilcox, R. R. (2015). Robust statistical methods: The R package WRS2. Retrieved from https://CRAN.R-project.org/package=WRS2.

Meiran, N. (1996). Reconfiguration of processing mode prior to task performance. Journal of Experimental Psychology: Learning, Memory and Cognition, 22, 1423-1442.

McFarlane, D. C., \& Latorella, K. A. (2002). The scope and importance of human interruption in human-computer interaction design. Human-Computer Interaction, 17, 1-61.

McQueen, E. N. (1917). The distribution of attention. British Journal of Psychology, Monographs Supplements 2.

Monk, C. A., Trafton, J. G., \& Boehm-Davis, D. A. (2008). The effect of interruption duration and demand on resuming suspended goals. Journal of Experimental Psychology: Applied, 14, 299-313.

Monsell, S. (2003). Task switching. Trends in Cognitive Neuroscience, 7(3), 134-140.

North, R. A., \& Gopher, D. (1976). Measures of attention as predictors of flight performance. Human Factors, 18(1), 1-14.

Neisser, U. (1963). The multiplicity of thought. British Journal of Psychology, 54, 1-14.

Oetingen, G. (2000). Expectancy effects on behavior depend on self-regulatory thought. Social Cognition, 18, 101-129. 
Oetingen, G., Pak, H., \& Schnetter, K. (2001). Self-regulation of goal setting: Turning free fantasies about the future into binding goals. Journal of Personality and Social Psychology, 80, 736-753.

Ophir, E., Nass, C., \& Wagner, A. D. (2009). Cognitive control in media multitaskers. Proceedings of the National Academy of Sciences, 106,15583-15587.

Orehek, E., \& Vazeou-Nieuwenhuis, A. (2013). Sequential and concurrent strategies of multiple goal pursuit. Review of General Psychology, 17(3), 339-349.

Oswald, F. L., Hambrick, D. Z., \& Jones, L. A. (2007). Keeping all the plates spinning: Understanding and predicting multitasking performance. In D. H. Jonassen (Ed.), Learning to solve complex scientific problems (pp. 77-96). Mahwah, NJ: Erlbaum.

Pashler, H. (1994). Dual-task interference in simple tasks: Data and theory. Psychological Bulletin, 2, 220-244.

Pashler, H. E. (1999). The psychology of attention. Cambridge, MA: MIT Press.

Pinheiro, J., Bates, D., DebRoy, S., Sarkar, D., \& R Core Team (2018). nlme: Linear and Nonlinear Mixed Effects Models. R package version 3.1-137. Retrieved from https://CRAN.R-project.org/package=nlme

Poposki, E. M. \& Oswald, F. L. (2010). The Multitasking Preference Inventory: Toward an Improved Measure of Individual Differences in Polychronicity. Human Performance, $23,247-264$.

Posner, M. I. (1990). Hierarchical distributed networks in the neuropsychology of selective attention. In A. Cramazza (Ed.), Cognitive neuropsychology and neurolinguistics (pp. 187e210). Hillsdale, NJ: Lawrence Erlbaum Associates.

Roberts, D. F., Foehr, U. G., \& Rideout, V. J. (2005). Generation M: Media in the lives of 818 year olds. Menlo Park, CA: Kaiser Family Foundation. 
Rogers, R., \& Monsell, S. (1995). The costs of a predictable switch between simple cognitive tasks. Journal of Experimental Psychology: General, 124, 207-231.

Roper, K. O., \& Juneja, P. (2008). Distractions in the workplace revisited. Journal of Facilities Management, 6(2), 91-109.

Rothbart, M. K. \& Posner, M. I. (2015). The developing brain in a multitasking world. Developmental Review, 35, 42-63.

Rubinstein, J. S., Meyer, D. E., \& Evans, J. E. (2001). Executive control of cognitive processes in task switching. Journal of Experimental Psychology: Human Perception and Performance, 27(4), 763-797.

Raby, M., \& Wickens, C. D. (1994). Strategic workload management and decision biases in aviation. International Journal of Aviation Psychology, 4, 211-240.

Salvucci, D.D. \& Taatgen, N. A. (2011). The Multitasking Mind. New York: Oxford University Press.

Sanbonmatsu, D. M., Strayer, D.L., Medeiros-Ward, N., \& Watson, J. M. (2013). Who MultiTasks and Why? Multi-Tasking Ability, Perceived Multi-Tasking Ability, Impulsivity, and Sensation Seeking. PLoS ONE, 8: e54402.

Sanjram, P. K., \& Khan, A. (2011). Attention, polychronicity, and expertise in prospective memory performance: Programmers' vulnerability to habit intrusion error in multitasking. International Journal of Human-Computer Studies, 69(6), 428-439.

Sankaran, S., Szumowska, E., \& Kossowska, M. (2017). "When the going gets tough, the tough get going": Motivation towards closure and effort investment in the performance of cognitive tasks. Motivation \& Emotion, 41(3), 308-321.

Schmidt, A. M., \& DeShon, R. P. (2007). What to do? The effects of discrepancies, incentives, and time on dynamic goal prioritization. Journal of Applied Psychology, 92, $928-41$. 
Segijn, C. M., Voorveld, H. A. M., Vandeberg, L., \& Smit, E. G. (2017). The battle of the screens. Unraveling attention allocation and memory effects when multiscreening. Human Communication Research, 43(2), 295-314.

Shah, J. Y. (2005). The automatic pursuit and management of goals. Current Directions in Psychological Science, 14, 10-13.

Shah, J. Y., Friedman, R., \& Kruglanski, A. W. (2002). Forgetting all else: on the antecedents and consequences of goal shielding. Journal of Personality and Social Psychology, 83(6), 1261-1280.

Shah, J. Y., \& Kruglanski, A. W. (2000). Aspects of goal networks: Implications for selfregulation. In M. Boekaerts, P. R. Pintrich, \& M. Zeidner (Eds.), Handbook of selfregulation (pp. 85-110). San Diego, CA: Academic Press.

Shah, J. Y., \& Kruglanski, A. W. (2003). When opportunity knocks: Bottom-up priming of goals by means and its effects on self-regulation. Journal of Personality and Social Psychology, 84(6), 1109-1122.

Shah, J. Y., \& Kruglanski, A. W. (2008). The challenge of change in goal systems. In J. Y. Shah, and W. L. Gardner (Eds.), Handbook of motivation science (pp. 217-229). New York, NY: Guilford Press.

Simon, H. A. (1967). Motivational and emotional controls of emotion. Psychological Review, 74, 29-39.

Solomons, L. M., \& Stein, G. (1896). Normal motor automatism. Psychological Review, 3, 492-512.

Speier, C., Valacich, J. S., \& Vessey, I. (1999). The Influence of Task Interruption on Individual Decision Making: An Information Overload Perspective. Decision Sciences, $30,337-360$. 
Speier, C., \& Vessey, I. \& Valacich, J. S., (2003). The effect of interruptions, task complexity, and information presentation on computer-supported decision-making performance. Decision Sciences, 34, 771-797.

Srivastava, J. (2013). Media multitasking performance: Role of message relevance and formatting cues in online environments. Computers in Human Behavior, 29, 888-895.

Szumowska, E., \& Kossowska, M. (2016). Need for closure and multitasking performance: The role of shifting ability. Personality and Individual Differences, 96, 12-17.

Szumowska, E., \& Kossowska, M. (2017). Motivational rigidity enhances multitasking performance: The role of handling interruptions. Personality and Individual Differences, 106, 81-89.

Szumowska, M., Kossowska, M., \& Roets, A. (2018). Motivation to comply with task rules and multitasking performance: The role of need for cognitive closure and goal importance. Motivation \& Emotion, 42(3), 360-376.

Szumowska, E., Popławska-Boruc, A., \& Kossowska, M. (2018). How many things do you (like to) do at once? The relationship between need for closure and multitasking preference and behavior. Personality and Individual Differences, 134, 222-231.

Szumowska, E., Popławska-Boruc, A., Kuś, J., Osowiecka, M., \& Kramarczyk, J. (2018). When frequent media multitaskers perform worse and when they do not: The role of self-regulation ability and strategy manipulation. Computers in Human Behavior, 83, 184-193.

Tindell, D. R., \& Bohlander, R. W. (2012). The use and abuse of cell phones and text messaging in the classroom: a survey of college students. College Teaching, 60(1), 1-9. Todorov, I., Del Missier, F., Konke, L.A., \& Mäntylä, T. (2015). Deadlines in space: Selective effects of coordinate spatial processing in multitasking. Memory \& Cognition, $43,1215-1228$. 
Vallerand, R. J. (2015). The psychology of passion: A dualistic model. Oxford.

Vancouver, J.B., Weinhardt, J.M., \& Schmidt, A.M. (2010). A formal, computational theory of multiple-goal pursuit: integrating goal-choice and goal-striving processes. Journal of Applied Psychology, 95, 985-1008.

van Der Schuur, W. A., Baumgartner, S. E., Sumter, S. R., \& Valkenburg, P. M. (2015). The consequences of media multitasking for youth: A review. Computers in Human Behavior, 53, 204-215.

Vroom, V. H. (1964). Work and motivation. New York: Wiley.

Waller, M. J. (2007). Preferences, behaviors, and strategies in multiple-task performance. Research in Multi-Level Issues, 6, 239-247.

Webster, D. M., \& Kruglanski, A. W. (1994). Individual differences in need for cognitive closure. Journal of Personality and Social Psychology, 67, 1049-1062.

Weick, K. E. (1968). Systematic observational methods. In G. Lindzey \& E. Aronson (Eds.), The handbook of social psychology (pp. 357-451). Reading, MA: Addison-Wesley.

Welch, J. (1898). On the measurement of mental activity through muscular activity and the determination of a constant of attention. American Journal of Physiology, 1, 288-306.

Wilcox, R. R. (2017). Introduction to Robust Estimation \& Hypothesis Testing. 4th edition. Amsterdam, The Netherlands: Elsevier.

Wilcox, R. R., \& Tian, T. (2011). Measuring Effect Size: A Robust Heteroscedastic Approach for Two or More Groups. Journal of Applied Statistics, 38, 1359-1368.

Wood, E., Zivcakova, L., Gentile, P., Archer, K., De Pasquale, D., \& Nosko, A. (2012). Examining the impact of off-task multi-tasking with technology on real-time classroom learning. Computers and Education, 58, 365-374. 
Yeykelis, L., Cummings, J. J., \& Reeves, B. (2014). Multitasking on a single device: Arousal and the frequency, anticipation, and prediction of switching between media content on a computer. Journal of Communication, 64(1), 167-192.

Yuen, K. K. (1974). The Two Sample Trimmed $t$ for Unequal Population Variances. Biometrika, 61, 165-170.

Zhang, Y., \& Fishbach, A. (2010). Counteracting obstacles with optimistic predictions. Journal of Experimental Psychology: General, 139(1), 16-31. 